Article

\title{
Reaction Kinetics and Coreflooding Study of High-Temperature Carbonate Reservoir Stimulation Using GLDA in Seawater
}

\author{
Khaled Z. Abdelgawad ${ }^{D}$, Mohamed Mahmoud*, Salaheldin Elkatatny ${ }^{\mathbb{D}}$, \\ Abdulazeez Abdulraheem and Shirish Patil \\ Petroleum Engineerig Department, King Fahd University of Petroleum \& Minerals, Dhahran 31261, Saudi Arabia \\ * Correspondence: mmahmoud@kfupm.edu.sa
}

Received: 11 July 2019; Accepted: 29 August 2019; Published: 4 September 2019

check for updates

\begin{abstract}
Well stimulation using hydrochloric acid $(\mathrm{HCl})$ is a common practice in carbonate reservoirs to overcome formation damage in the near wellbore area. Using $\mathrm{HCl}$ for matrix acidizing has many limitations at high-temperature (HT) conditions, such as tubulars corrosion and face dissolution due to the fast reaction rate. Chelating agents, such as L-glutamic acid-N,N-diacetic acid (GLDA), are alternatives to $\mathrm{HCl}$ to overcome these problems. We studied the effect of diluting GLDA in seawater on the reaction kinetics with carbonate rocks under HT conditions at low $\mathrm{pH}$ (3.8). Results of the reaction of carbonate at 1000 psi and 150, 200, and $250^{\circ} \mathrm{F}$ with GLDA prepared in both fresh and seawater, GLDA/DI and GLDA/SW, respectively, are presented. The reaction kinetics experiments were carried out in HT rotating disk apparatus (RDA) at rotational speeds ranging from 500 to 2000 revolutions per minute (RPM) at a fixed temperature. Indiana limestone and Austin chalk were used to studying the effect of rock facies on the reaction of GLDA with rock samples. In both GLDA/DI and GLDA/SW, the reaction regime of $20 \mathrm{wt} \%$ GLDA (3.8 pH) with Indiana limestone was mass transfer limited. The reaction rate and diffusion coefficient were highly dependent on the temperature. For Austin chalk, at $200{ }^{\circ} \mathrm{F}$ and 1000 psi the diffusion coefficient of GLDA/SW is an order of magnitude of its value with Indiana limestone using the same fluid. Diffusion coefficients were used to estimate the optimum injection rate for stimulating HT carbonate formation and compared with coreflooding results. The data presented in this paper will support the numerical simulation of the acid flow in carbonate reservoirs.
\end{abstract}

Keywords: well stimulation; chelating agents; production enhancement; environmental friendly stimulation fluid; seawater

\section{Introduction}

Organic and inorganic acids are often injected into carbonate reservoirs to improve oil and gas production. These acids are usually selected based on the type of reservoir rock. In the case of stimulating carbonate formations, acids can dissolve the carbonate rock matrix and create different dissolution features or structures depending on the acid type, injection rate, and formation conditions [1-6]. Face-dissolution usually results from very low injection rates which give more time for dissolution of the rock face a pattern [7]. When the retention time of acid in the rock is small, narrow dissolution channels are formed and propagate through the rock and form more branches with continuous acid injection [8,9]. An optimum channel formed during acid injection at the minimum volume of acid injected and yield the highest permeability increase is known as a wormhole $[4,10,11]$. Other dissolution patterns may present, such as conical wormholes, at an injection rate between face dissolution and the optimum wormhole, and ramified wormholes at an injection rate between the optimum wormhole and uniform dissolution patterns. 
The acid type affects the structure of wormholes generated during carbonate acidizing $[7,12]$. Slow reacting acids, such as chelating agents and other organic acids form wider, less branched wormholes, while highly reactive acids, such as $\mathrm{HCl}$, form highly branched wormholes [13]. The relative magnitudes of acid transport and reaction rates define the controlling step of the dissolution reaction whether kinetically controlled or mass-transfer controlled [14]. As a result, the wormhole structure depends on the acid diffusivity and reactivity, in addition to the acid-injection rate [15]. To characterize acid transport to rock surface during matrix acidizing, the acid diffusion coefficient is an important parameter to be determined under reservoir conditions [16].

\section{Chelating Agents}

Chelating agents can sequester metal ions through coordination bonds and prevent any further interaction with other ions present in the solution. The chelating agent type and the metal ion properties highly affect the stability of the formed organic [17].

The low corrosiveness nature of chelating agents enables using it in different aspects of the oil and gas industry including scale removal from electrical submersible pumps in oil production wells [18], Scale inhibition [19,20], Filter cake removal after drilling operations [21]. In addition, aminocarboxylic acids were used to improve oil recovery from subsurface hydrocarbon reservoirs [22,23]. Different chelating agents were also used as standalone stimulation fluids at a wide range of $\mathrm{pH}$ values at high-pressure high-temperature (HPHT) conditions [24,25].

GLDA is an aminopolycarboxylic acid (Figure 1), which can form stable complexes with different alkali earth metals ( $\mathrm{Ca}, \mathrm{Fe}, \mathrm{Mg}$, etc.) with a low corrosiveness to the equipment up to $300{ }^{\circ} \mathrm{F}$ [26]. It is produced from a bio-based naturally-occurring amino acid known as monosodium L-glutamic acid. GLDA is favorable because of its improved biodegradability properties, such as being readily biodegradable with high solubility in fresh water over a wide $\mathrm{pH}$ range [27]. Studies were done before proved the effectiveness of using GLDA for well stimulation in both sandstone and carbonate reservoirs $[26,28,29]$. Limitation of using EDTA in seawater base is chemical precipitation at low $\mathrm{pH}$ values while GLDA can be prepared in sweater at high concentrations (up to $20 \mathrm{wt} \%$ ) without any precipitation problems [30]. For these reasons, GLDA was selected as the stimulation fluid in this study because of its high stability at higher concentration commonly used for matrix acidizing and lower $\mathrm{pH}$ when prepared in seawater.

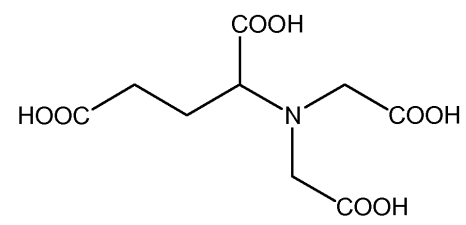

Figure 1. Glutamic acid, N, N-diacetic acid (GLDA) chemical structure, the acid form was used in this paper at $\mathrm{pH} 3.8$.

GLDA undergoes stepwise deprotonation to reach a fully ionized state. The calcite dissolution rate by the GLDA chelating agent depends on the GLDA pH. The form of the ionic species of GLDA is dictated by a dissociation reactions series. For GLDA (a chelating agent with four carboxylic acid groups), the acid dissociation constants (pKa) values at an ionic strength of $0.1 \mathrm{M}$ and $25{ }^{\circ} \mathrm{C}$ are shown in Table 1 in which $\mathrm{H}_{\mathrm{m}} \mathrm{Y}^{\mathrm{m}-\mathrm{n}}$ is the chelating agent molecule, $\mathrm{m}$ is the number of acidic protons, and $\mathrm{n}$ is number of carboxylic acid groups, i.e., 4. Reaction of high GLDA pH solutions $\left(\mathrm{Y}^{-4}\right)$ are primarily driven by the chelation process, which generally has a much lower reaction rate than the acid dissolution process and gives 1:1 ratio between the chelate and calcium ions. In the intermediate $\mathrm{pH}$ range, both processes will contribute to the overall dissolution rate. As $\mathrm{pH}$ increases from 1.7 to 13 , the GLDA successively deprotonated from $\mathrm{H}_{4} \mathrm{Y}$ to $\mathrm{Y}^{-4}$ thereby losing the ability to donate $\mathrm{H}^{+}$ions as $\mathrm{pH}$ increased. The reaction rate of GLDA at high $\mathrm{pH}$ values is dominated by chelation and is expected to be significantly slower than that at low $\mathrm{pH}$ values. 
Table 1. The acid dissociation constants (pKa) for $0.1 \mathrm{M}$ GLDA at $25^{\circ} \mathrm{C}$ [31].

\begin{tabular}{cc}
\hline Dissociation & pKa \\
\hline $\mathrm{H}_{4} \mathrm{Y} \rightleftharpoons \mathrm{H}_{3} \mathrm{Y}^{-1}+\mathrm{H}^{+}$ & $\mathrm{pKa}_{1}=9.4$ \\
$\mathrm{H}_{3} \mathrm{Y}^{-1} \rightleftharpoons \mathrm{H}_{2} \mathrm{Y}^{-2}+\mathrm{H}^{+}$ & $\mathrm{pKa}_{2}=5.0$ \\
$\mathrm{H}_{2} \mathrm{Y}^{-2} \rightleftharpoons \mathrm{HY}^{-3}+\mathrm{H}^{+}$ & $\mathrm{pKa}_{3}=3.5$ \\
$\mathrm{HY}^{-3} \rightleftharpoons \mathrm{Y}^{-4}+\mathrm{H}^{+}$ & $\mathrm{pKa}_{4}=2.6$ \\
\hline
\end{tabular}

GLDA showed promising results when used to stimulate HPHT carbonate and sandstone reservoirs in many laboratory studies $[26,27,32]$ as well as field treatments $[33,34]$. GLDA is being used as an alternative to $\mathrm{HCl}$ in order to overcome the challenges of HPHT environments such as well tubulars corrosion, face dissolution due to uncontrolled high reaction rate, and formation damage due to sludge formation. In addition, GLDA also acts as an iron control agent and it is less corrosive to the well tubulars. $\mathrm{HCl}$ needs numerous additives, which will increase the cost of the matrix acidizing. $\mathrm{HCl}$ based matrix acidizing formulations are usually loaded with additives, such as corrosion inhibitors, water-wetting surfactants, iron control agent, anti-sludge agents, iron control agents, etc. GLDA acid treatment does not require any additives since GLDA itself acts as iron control agent, has low interfacial tension (IFT), acts as surfactant, and does not cause asphaltene precipitation [35]. Using GLDA will eliminate the need for the numerous additives used in the case of $\mathrm{HCl}$ treatment.

Performing the reaction kinetics experiments of stimulation fluids using RDA will enable the optimization of tedious and expensive coreflooding experiments and will facilitate the stimulation design for any damage radius. To locate the optimum injection rate for each damage penetration, several corefloods are needed. For example, the optimum injection rate and hence the optimum Damköhler number can be determined using the diffusion coefficient of the mass transfer limited reactions. The diffusion coefficient is obtained from a series of reaction kinetics experiments using the RDA.

To the authors' knowledge, this is the first time to report the reaction kinetics of GLDA chelating agent prepared in seawater with calcite rock samples using RDA at HPHT. The reaction regimes and the diffusion coefficients of GLDA are determined. In addition, we investigate the effect of porosity type (rock facie) on the rock fluid interaction by comparing the reaction of two different carbonate rocks having similar mineralogy but different porosity type with the same fluid system.

\section{Rotating Disk Theory}

During a matrix acidizing treatment, an acidic fluid is injected into the reservoir rock, the reaction regime is greatly affected by both reactant and products transport to and from the rock surface [14]. The three steps making the overall reaction are (Figure 2):

- Reactant transport to the rock surface.

- Reaction at the rock surface.

- Products transport from the rock surface.

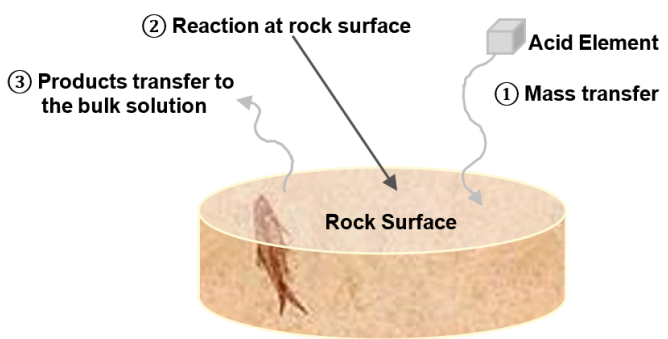

Figure 2. Acid reaction with the rock surface. 
The slowest step is known as "the rate-limiting step" since it will control the overall reaction kinetics. For example, if the surface reaction rate is slower than the mass transfer process, then the reaction is surface reaction limited [36]. On the other hand, if the reactants and products diffusion to/from the surface is slower than the surface reaction rate, the process is mass transfer limited.

In the case of Newtonian fluids, the mass transfer rate $\left(R_{M T}\right)$ of a reactant to the solid surface in a laminar flow regime induced by a rotating disk geometry is given by the following Equation $[37,38]$ :

$$
\begin{gathered}
J_{m t}=k_{m}\left(C_{b}-C_{s}\right) \\
k_{m}=\frac{0.60248\left(S_{c}^{-\frac{2}{3}}\right) \sqrt{v \omega}}{1+0.2980\left(S_{c}^{-\frac{1}{3}}\right)+0.1451\left(S_{c}^{-\frac{2}{3}}\right)}
\end{gathered}
$$

where $J_{m t}$ is the mass transfer flux, $C_{b}$ is the transferred species bulk concentration, $C_{s}$ is the transferred species surface concentration, $k_{m}$ is the mass transfer coefficient, $\omega$ is disk angular velocity (equal to $2 \pi \mathrm{N}, \mathrm{N}$ is the number of cycles/s or rad/s), $\rho$ is the density of the bulk fluid $\left(\mathrm{gm} / \mathrm{cm}^{3}\right), \mu$ is the viscosity of the bulk fluid $(\mathrm{gm} / \mathrm{s.cm}), v$ is the kinematic viscosity $\left(\mathrm{cm}^{2} / \mathrm{s}\right), S_{c}$ is Schmidt number $\left(v / D_{e}\right)$, dimensionless, and $D_{e}$ is the diffusion coefficient $\left(\mathrm{cm}^{2} / \mathrm{s}\right)$.

For reactions limited by mass transfer, $C_{s}$ can be neglected $\left(C_{s} \approx 0\right)$. Then Equation $(1)$ can be written as:

$$
J_{m t}=\frac{0.60248\left(\frac{\mu}{\rho D_{e}}\right)^{-\frac{2}{3}} C_{b} \sqrt{\frac{\mu}{\rho}}}{1+0.2980\left(\frac{\mu}{\rho D_{e}}\right)^{-\frac{1}{3}}+0.1451\left(\frac{\mu}{\rho D_{e}}\right)^{-\frac{2}{3}}} \omega^{\frac{1}{2}}
$$

For laminar flow regime around a rotating disk, Reynold's number is in the order of $10^{4}-10^{5}$ and is defined as [37]:

$$
N_{R e}=\frac{\omega R^{2}}{v}
$$

where $R$ is the radius of the rotating disk $(\mathrm{cm})$. For the RDA reactor's geometry, the laminar flow occurs when Reynold number is below $3 \times 10^{5}$ compared to 2000 in pipe flow [39,40]. In this work Equation (3) was used to interpret the results as $N_{R e}$ is less than $10^{4}$ (highest $N_{R e}$ is 804 at $2000 \mathrm{RPM}$ ). In addition, the fluids used (20 wt $\%$ GLDA/DI and $20 \mathrm{wt} \%$ GLDA/SW) are Newtonian fluids [31]. The surface reaction rate can be described as a function of concentration by the following Equation [41]:

$$
-r_{H C l}=k C_{A s}^{n}=J_{m t}
$$

where $r_{H C l}$ is the dissolution rate per unit area $\left(\mathrm{moles} / \mathrm{cm}^{2} \cdot \mathrm{s}\right), k$ is the Specific reaction rate $\left(\mathrm{moles} / \mathrm{cm}^{2} \cdot \mathrm{s}\right)\left(\mathrm{mole} / \mathrm{cm}^{3}\right)^{-\mathrm{n}}, C_{A s}$ is the concentrations of the dissolving substance (A) at the reaction surface $\left(\mathrm{moles} / \mathrm{cm}^{3}\right)$, and $\mathrm{n}$ is reaction order which is dimensionless. GLDA in the acidic form will react mainly by hydrogen attack in addition to chelation. This equation describes the reaction of adsorbed $\mathrm{H}^{+}$with the solid surface. The dissolution rate is the slope of the straight line between calcium concentration and time fitted to each experimental divided by the initial surface area of the core sample face [42]:

$$
R=\frac{1}{(1-\phi) A_{\text {core }}} \frac{d C_{A}}{d t}
$$

where $R$ is the dissolution rate of calcite in acid per unit area $\left(\mathrm{mole} / \mathrm{cm}^{2} \cdot \mathrm{s}\right), C_{A}$ is the concentration of the substance A (calcium, in our case), $t$ is the time (s), $A_{\text {core }}$ is the rock sample surface area exposed to acid $\left(\mathrm{cm}^{2}\right)$, and $\phi$ is the rock sample porosity (fraction). For all the used samples, the rock surface area to be exposed to the reaction was polished using sandpaper to reduce the error of surface area estimation. If the reaction is limited by the mass transfer of the reactants or the products, increasing $\omega$ increases the mass transfer and, in turn, the dissolution rate will increase. If the mass transfer rate is 
higher than the rate of acid consumption on the rock surface, the overall dissolution is independent of $\omega$ and the regime is surface reaction limited [43].

\section{Materials and Methodology}

\subsection{Rock Samples and Fluids}

Acidizing treatments usually target low permeability zones due to formation damage in the near wellbore. Usually formation damage occurs after starting production and obtaining core samples from a completed well is very difficult if not impossible. In addition, long samples are needed for coreflooding to be able to accurately detect the pressure drop across the sample and define the wormhole breakthrough. Having this in mind, we screened many Indiana limestone samples and selected the samples with low permeability for both the reaction kinetics and coreflooding experiments so that the experimental results can be interpreted and integrated from both rotating disk and coreflooding. Austin chalk samples were selected as they have almost $100 \% \mathrm{CaCO}_{3}$ mineralogy similar to Indiana limestone while having different facies compared to Indiana limestone. In all experiments $20 \mathrm{wt} \%$ GLDA was used for the reasons mentioned in Section 2 in this paper.

\subsection{Methodology}

To study the reaction kinetics of both $20 \mathrm{wt} \%$ GLDA/DI and $20 \mathrm{wt} \%$ GLDA/SW, a HPHT rotating disk apparatus (Figure 3) was used. The RDA system was designed inhouse at king Fahd university of Petroleumand Minerals and assembled by Hi-Tech Engineering, Morbi, Gujarat, India. The system was designed to allow collecting consecutive samples at a certain time step from the bulk solution during stirring a rock sample at a fixed angular velocity inside the stimulation fluid under HPHT. Additionally, the design allows the contact between the rock sample and the fluid only at the face of the rock by using a harsh environment shrinkage tube which attaches the rock to the rotating disk and also covers all the sides of the sample except the front face of the rock sample. The RDA and the experimental details were comprehensively described in our previous paper [44]. During each experiment, the flux $\left(J_{m t}\right)$ is determined from the analysis of the measured calcium ions concentration in the collected samples. The experiment is then repeated at different angular velocities with all other parameters constant (i.e., temperature and acid concentration).

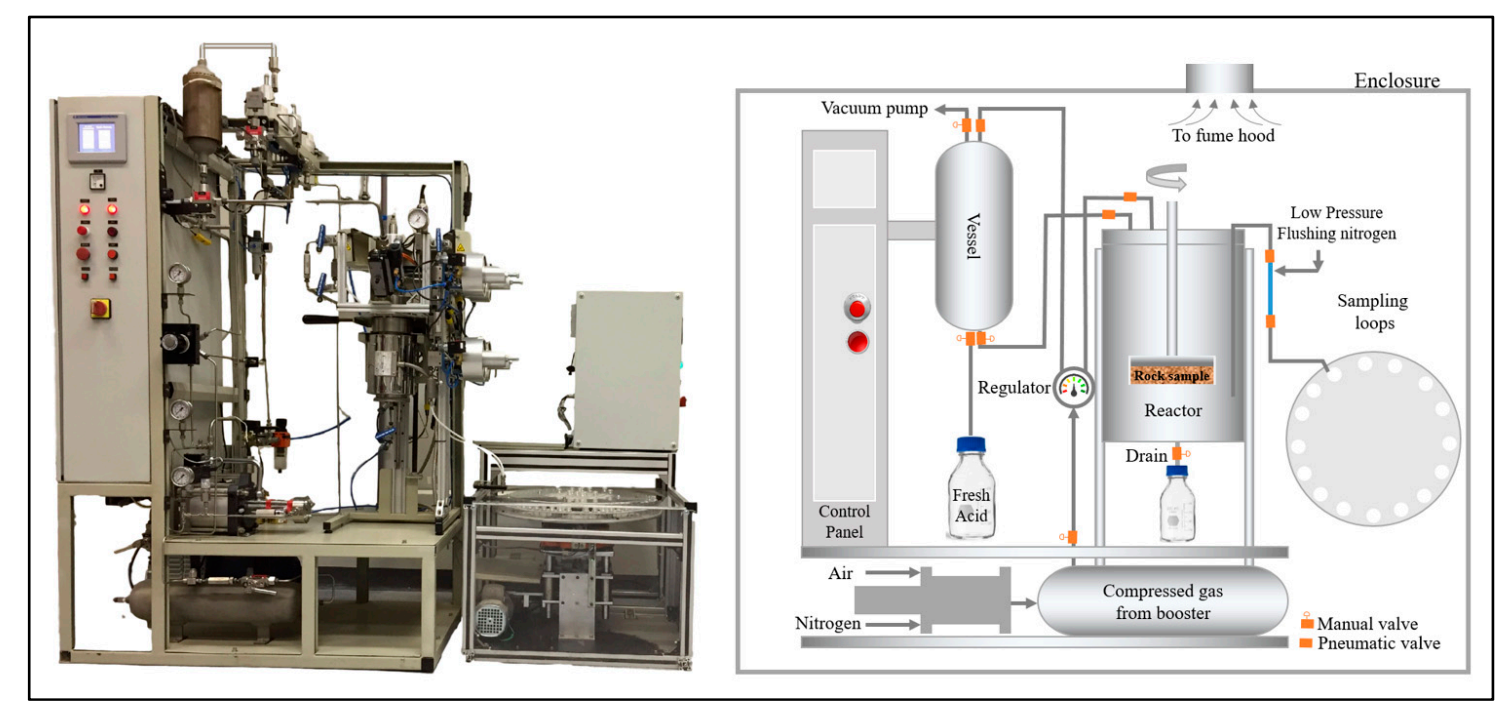

Figure 3. Rotating disk apparatus with a schematic showing the main components.

The approach for defining the limiting step for the reaction of $20 \mathrm{wt} \%$ GLDA chelating agent at $3.8 \mathrm{pH}$ solution with carbonate rock is shown in Figure 4. The calcium concentration in ppm is plotted versus time for each angular velocity. The limiting step of the reaction is determined by plotting the 
dissolution rate (slope of calcium concentration curve versus time) versus the square root of the disk angular velocity for each rock/fluid system at a fixed temperature. A constant slope indicates a mass transfer limited reaction with slow diffusion of reactants and products compared to a zero slope in case of surface reaction limited dissolution where the diffusion of reactants and products is much faster than the dissolution reaction at the rock surface.

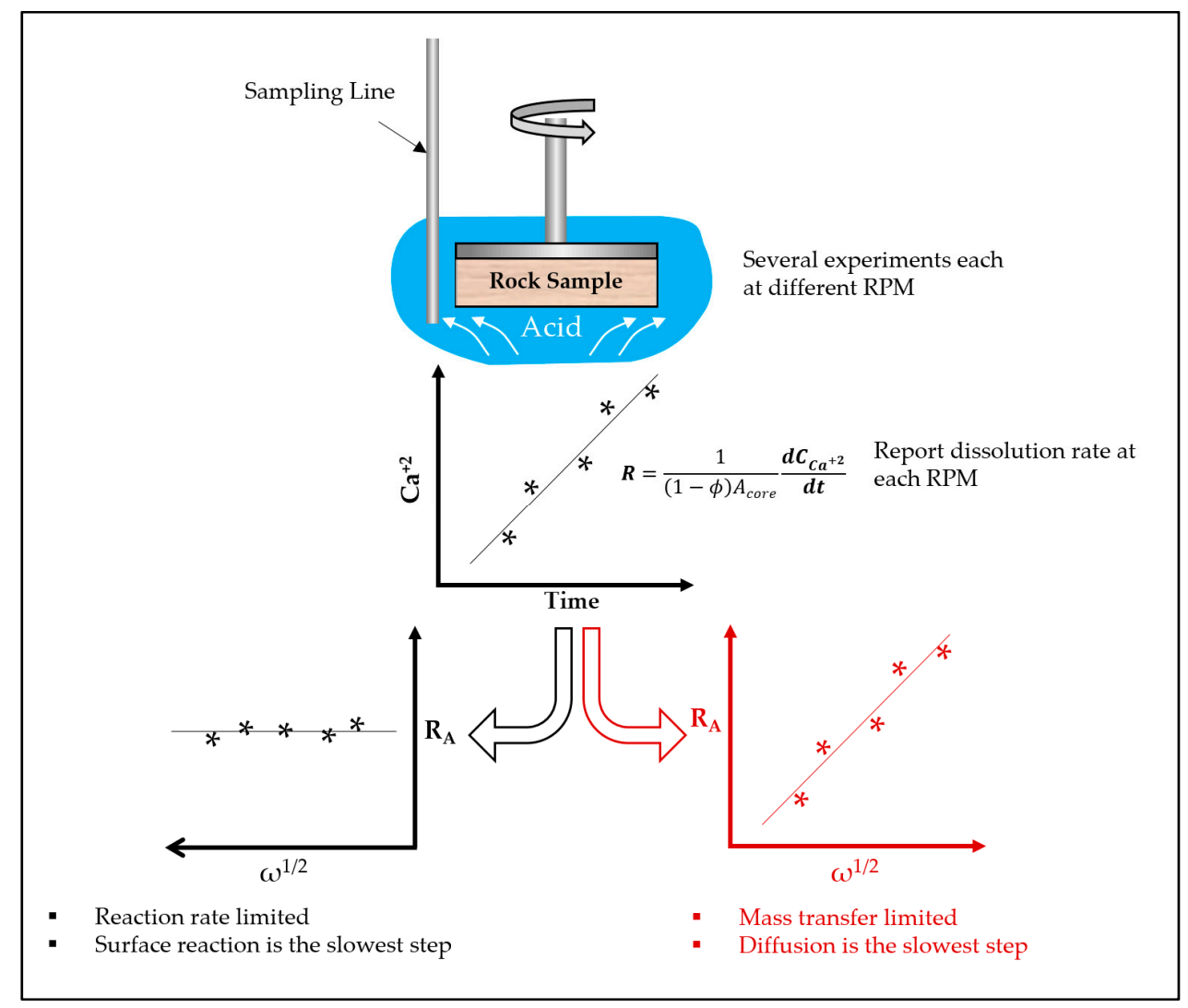

Figure 4. The systematic approach of defining the reaction-limiting step using RDA [44].

\section{Experimental Work}

\subsection{Rock Samples Preparation}

Both Indiana limestone and Austin chalk core samples of 0.8-inch-long, 1.5-inch diameter were used. For each sample, the faces were polished to assure a smooth surface for reaction using end face grinding, polishing, and sonic cleaning. The porosity of each sample was calculated using dry and saturated weights.

\subsection{RDA Experiments}

Two sets of experiments were designed to study the dissolution rate of carbonate rock using GLDA using RDA. In one set, the stock GLDA concentration of $40 \mathrm{wt} \%$ was diluted using deionized water was to $20 \mathrm{wt} \%$ at $(3.8 \mathrm{pH})$. While on the other set of experiments synthetic gulf water with the composition listed in Table 2 was used to dilute GLDA to $20 \mathrm{wt} \%$. 
Table 2. Synthetic gulf water composition [44].

\begin{tabular}{cc}
\hline Ions & Concentration $(\mathbf{m g} / \mathbf{L})$ \\
\hline Sodium & 18,300 \\
Calcium & 650 \\
Magnesium & 2110 \\
Sulfate & 4290 \\
Chloride & 32,200 \\
Carbonate & 0 \\
Bicarbonate & 120 \\
Total dissolved salts (TDS) & 57,670 \\
\hline
\end{tabular}

For each set, four experiments were carried out constant pressure (1000 psi), temperature, and different disk rotational speeds (500, 1000, 1500, and 2000 RPM). A $500 \mathrm{~mL}$ of the chelating agent at final concentration $(20 \mathrm{wt} \%)$ was used in each experiment. The density and viscosity of $20 \mathrm{wt} \%$ of GLDA/DI and GLDA/SW as a function of temperature are shown in Figure 5. These properties are required when Equation (3) is to be applied. The experimental sets where repeated at different temperatures in the same way (Table 3). Experiments 1-24 were done for the comparison of DI to seawater on Indiana limestone at $150-250^{\circ} \mathrm{F}$. Experiments 17-20 and experiments 25-28 were carried out for comparison of Indiana limestone to Austin chalk using GLDA/SW system at $200^{\circ} \mathrm{F}$. During each experiment, ten liquid samples of $3 \mathrm{~mL}$ volume were collected at a time interval of two minutes. An inductively-coupled plasma optical emission spectroscopy (ICP-OES) Optima 8000 model by PerkinElmer, Waltham, Massachusetts, United States was used to measure the calcium concentration in each sample.

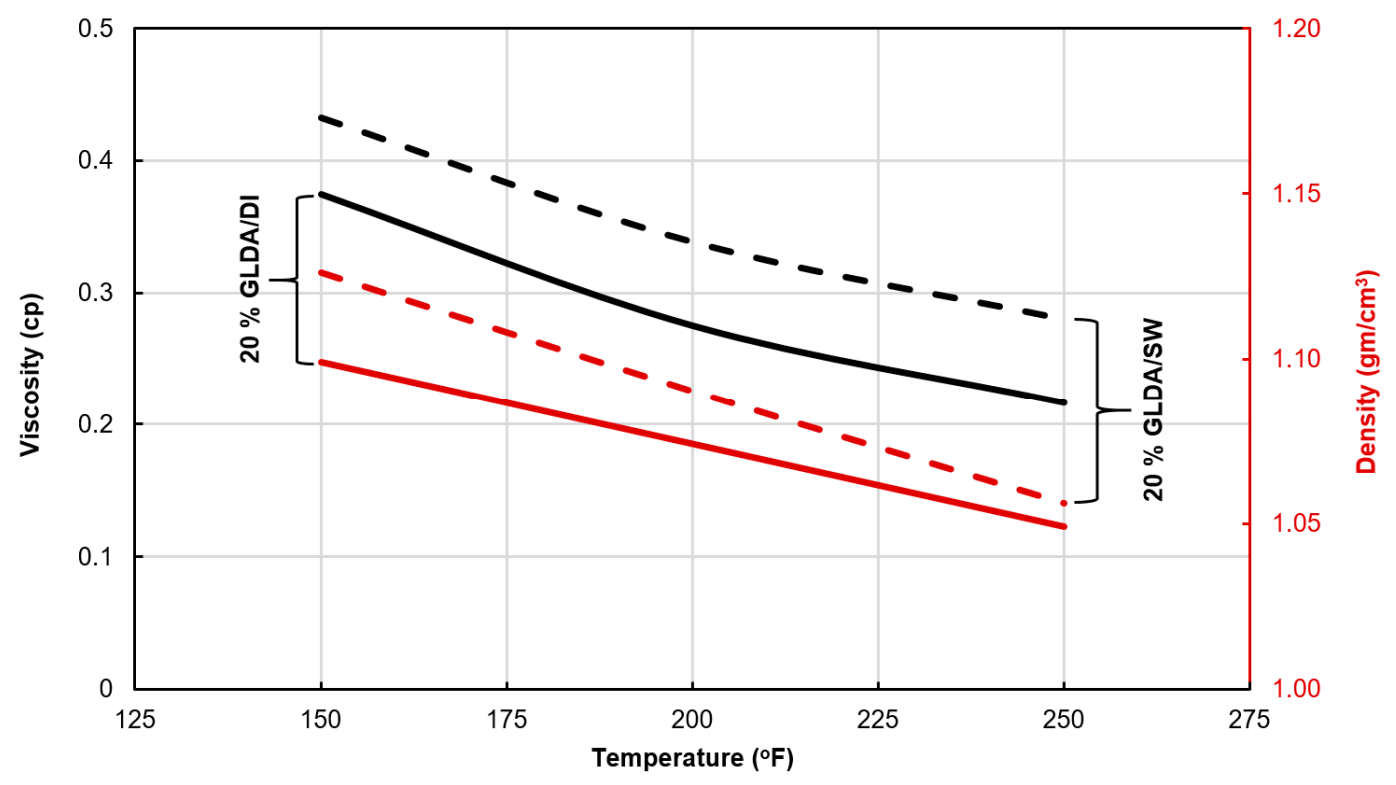

Figure 5. Density and viscosity of $20 \mathrm{wt} \%$ GLDA $(3.8 \mathrm{pH})$ prepared in seawater and DI water as a function of temperature. 
Table 3. Experiments using GLDA with Indiana limestone and Austin chalk calcite roks.

\begin{tabular}{|c|c|c|c|c|}
\hline $\begin{array}{c}\text { Experiment } \\
\text { No. }\end{array}$ & Fluid/Rock & $\begin{array}{c}\text { Temperature } \\
\left({ }^{\circ} \mathrm{F}\right)\end{array}$ & $\begin{array}{c}\text { Disk Porosity } \\
(\%)\end{array}$ & $\begin{array}{l}\text { Disk Angular } \\
\text { Velocity (RPM) }\end{array}$ \\
\hline 1 & \multirow{12}{*}{$\begin{array}{c}20 \mathrm{wt} \% \\
\text { GLDA/DI/Indiana } \\
\text { Limestone }\end{array}$} & \multirow{4}{*}{150} & 6.82 & 500 \\
\hline 2 & & & 6.82 & 1000 \\
\hline 3 & & & 7.07 & 1500 \\
\hline 4 & & & 7.15 & 2000 \\
\hline 5 & & \multirow{4}{*}{200} & 10.02 & 500 \\
\hline 6 & & & 9.62 & 1000 \\
\hline 7 & & & 10.14 & 1500 \\
\hline 8 & & & 9.20 & 2000 \\
\hline 9 & & \multirow{4}{*}{250} & 9.08 & 500 \\
\hline 10 & & & 9.99 & 1000 \\
\hline 11 & & & 6.75 & 1500 \\
\hline 12 & & & 9.46 & 2000 \\
\hline 13 & \multirow{12}{*}{$\begin{array}{c}20 \mathrm{wt} \% \\
\text { GLDA/SW } \\
\text { with Indiana } \\
\text { Limestone }\end{array}$} & \multirow{4}{*}{150} & 12.41 & 500 \\
\hline 14 & & & 9.42 & 1000 \\
\hline 15 & & & 9.75 & 1500 \\
\hline 16 & & & 9.43 & 2000 \\
\hline 17 & & \multirow{4}{*}{200} & 9.30 & 500 \\
\hline 18 & & & 9.55 & 1000 \\
\hline 19 & & & 9.66 & 1500 \\
\hline 20 & & & 6.916 & 2000 \\
\hline 21 & & \multirow{4}{*}{250} & 9.24 & 500 \\
\hline 22 & & & 9.53 & 1000 \\
\hline 23 & & & 9.53 & 1500 \\
\hline 24 & & & 12.41 & 2000 \\
\hline 25 & \multirow{4}{*}{$\begin{array}{c}20 \mathrm{wt} \% \\
\text { GLDA/SW } \\
\text { with Austin Chalk }\end{array}$} & \multirow{4}{*}{200} & 26.07 & 500 \\
\hline 26 & & & 22.45 & 1000 \\
\hline 27 & & & 27.96 & 1500 \\
\hline 28 & & & 26.79 & 2000 \\
\hline
\end{tabular}

\section{Results and Discussion}

\subsection{Indiana Limestone}

The analysis of the first four experiments (Figure 6a) shows that the reaction regime for the $20 \%$ GLDA/DI and Indiana limestone rock samples is surface reaction limited at $150^{\circ} \mathrm{F}$. Increasing the temperature from $150^{\circ} \mathrm{F}$ to $200^{\circ} \mathrm{F}$ increased the surface reaction and turned the reaction to be mass transfer limited regime (Figure 6b). The same temperature effect is also obvious at $200{ }^{\circ} \mathrm{F}$ (Figure $6 \mathrm{c}$ ). Figure $6 \mathrm{~d}$ summarizes the results of $20 \%$ GLDA/DI reaction with Indiana limestone core samples at 150,200 , and $250^{\circ} \mathrm{F}$. 

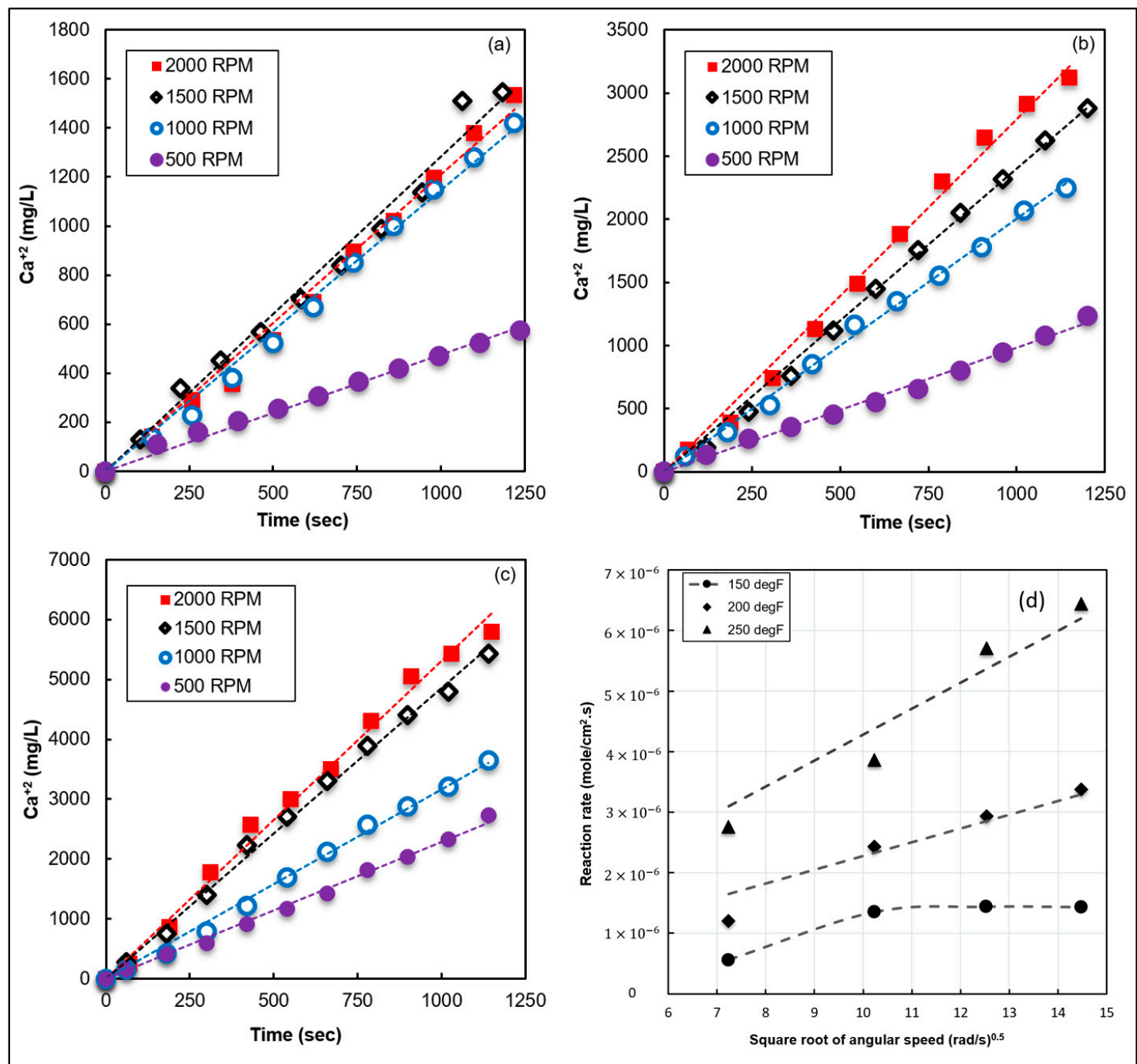

Figure 6. The concentration of calcium in the collected fluid samples as a function of time and rotation speed using $20 \mathrm{wt} \% \mathrm{GLDA} / \mathrm{DI}$ solution at $150{ }^{\circ} \mathrm{F}(\mathbf{a}), 20{ }^{\circ} \mathrm{F}(\mathbf{b})$, and $\left(250{ }^{\circ} \mathrm{F}\right)(\mathbf{c})$, and rate of calcite dissolution in $20 \mathrm{wt} \%$ GLDA/DI at $\mathrm{pH} 3.8$ at corresponding temperatures (d).

Applying Equation (3), diffusion coefficients of $4.59 \times 10^{-6}$ and $1.07 \times 10^{-5} \mathrm{~cm}^{2} / \mathrm{s}$ are obtained at 200 and $250^{\circ} \mathrm{F}$ respectively. On the other hand, the reaction of $3.8 \mathrm{pH}, 20 \mathrm{wt} \% \mathrm{GLDA} / \mathrm{SW}$ with Indiana limestone core samples is mass transfer limited regime at all temperatures $\left(150,200\right.$, and $\left.250{ }^{\circ} \mathrm{F}\right)$ as shown in Figure $7 \mathrm{a}-\mathrm{d}$. This is attributed to the high mass transfer resistance due to high salinity. Applying Equation (7), diffusion coefficients of $8.31 \times 10^{-7}, 3.3712 \times 10^{-6}$, and $4.71029 \times 10^{-6} \mathrm{~cm}^{2} / \mathrm{s}$ are obtained at 150,200 , and $250^{\circ} \mathrm{F}$, respectively. The diffusion coefficient in case of GLDA/SW is smaller compared to GLDA/DI because the chemical species diffusion is buffered by the salts presents in GLDA/SW system. The relation between the effective diffusion coefficient and temperature (Equation (7)) is obtained by fitting a linear equation to the black dashed straight line in Figure 8.

$$
D_{e}=3.88 \times 10^{-8} \mathrm{~T}-4.79 \times 10^{-6}
$$




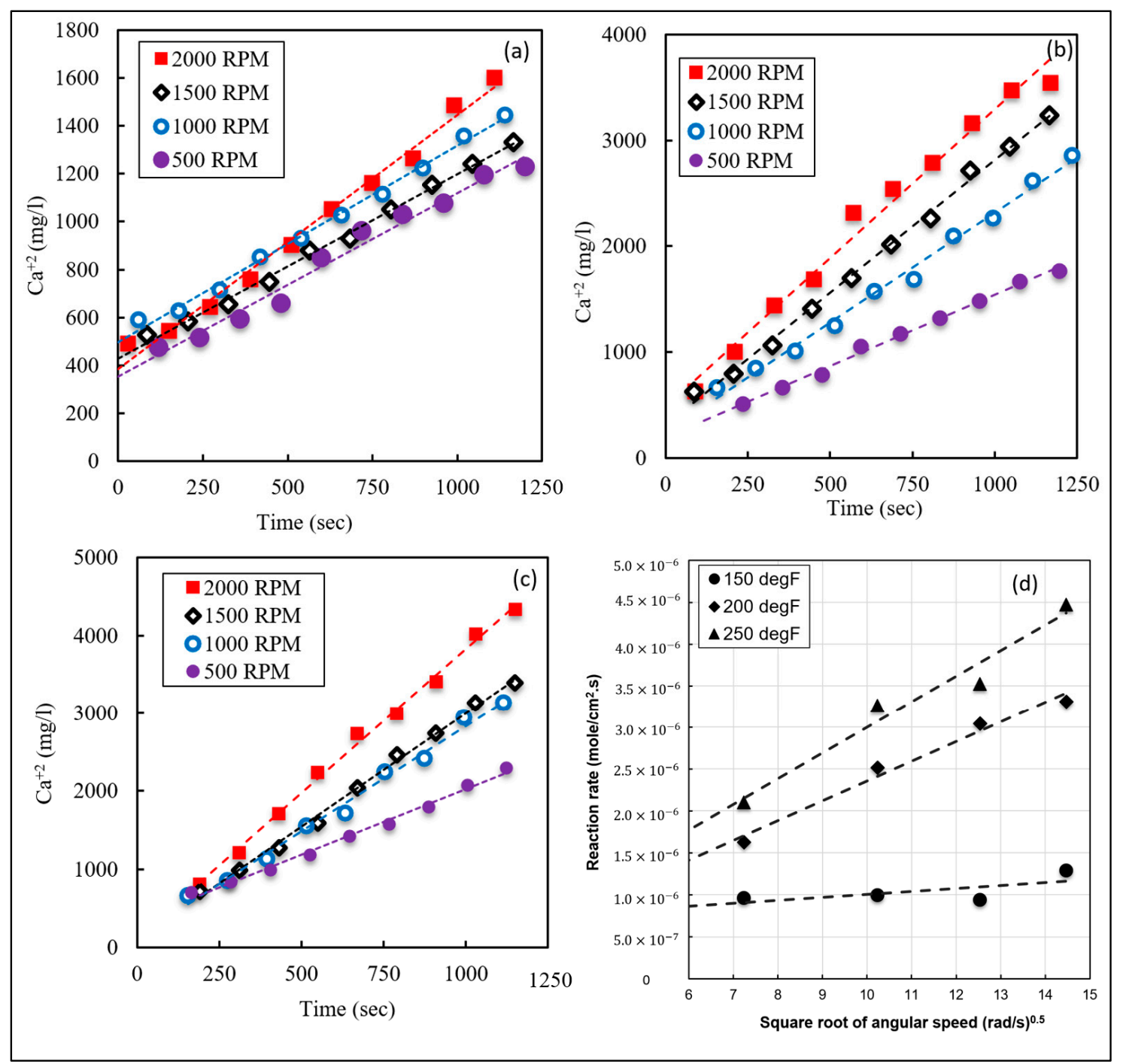

Figure 7. The concentration of calcium in the collected fluid samples as a function of time and rotation speed using $20 \mathrm{wt} \% \mathrm{GLDA} / \mathrm{SW}$ solution at $150{ }^{\circ} \mathrm{F}(\mathbf{a}), 200^{\circ} \mathrm{F}(\mathbf{b})$, and $250{ }^{\circ} \mathrm{F}(\mathbf{c})$, and the rate of calcite dissolution by $20 \mathrm{wt} \% \mathrm{GLDA} / \mathrm{SW}$ ( $\mathrm{pH} 3.8$ ) at corresponding temperatures (d). 


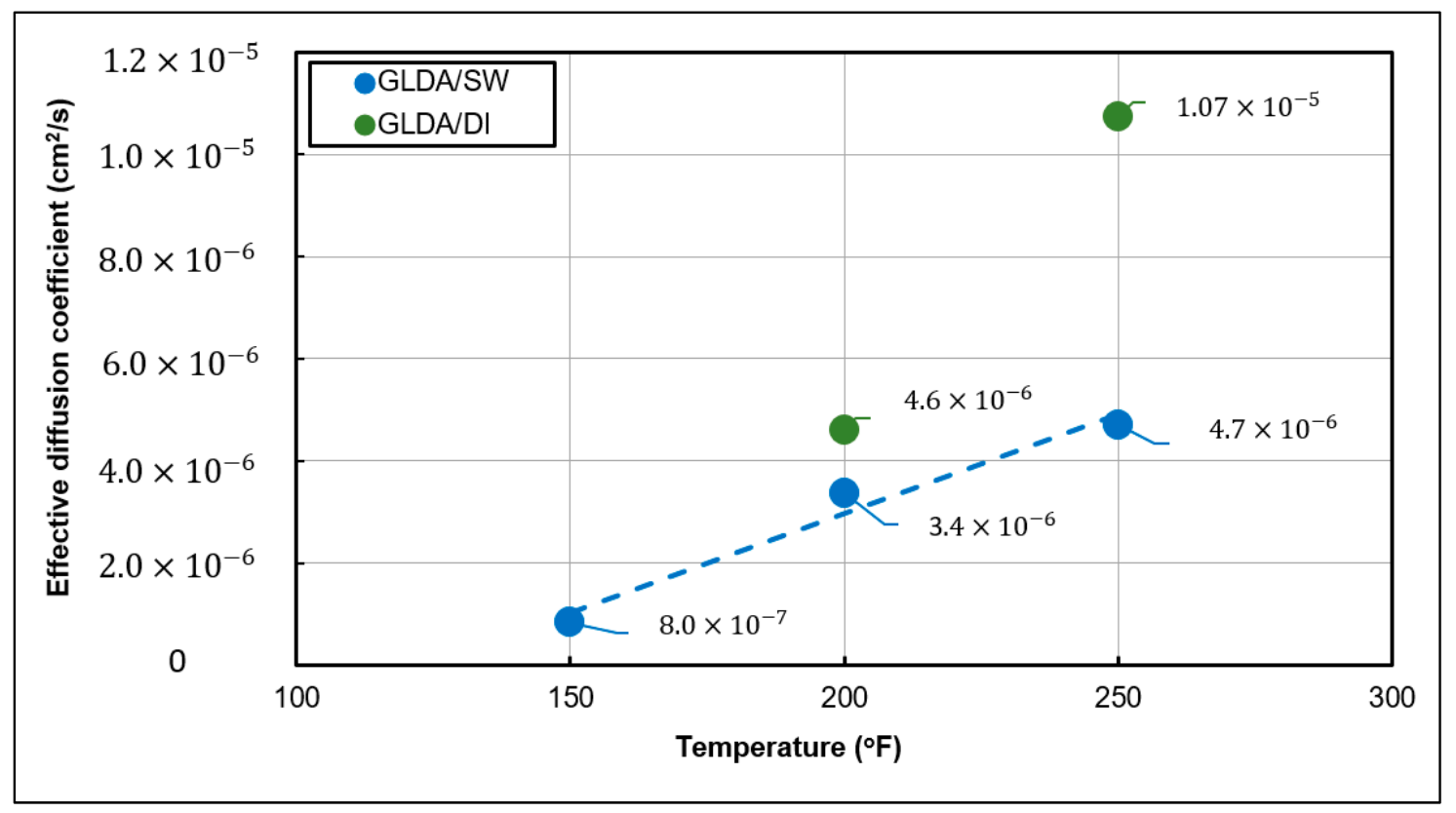

Figure 8. Diffusion coefficient of $20 w t \%$ GLDA/DI and GLDA/SW as a function of temperature for Indiana limestone.

Equation (7) is based on three data points for seawater covering the temperature range from $150-250^{\circ} \mathrm{F}$. The Temperature increase in the case of GLDA/DI from 200 to $250^{\circ} \mathrm{F}$ highly significantly increased $D_{e}$. The reduction in acid diffusion can be attributed to the high calcium concentration chelated in the solution. This acts as a restriction and slowed down the diffusion of GLDA making the mass transfer is the limiting step. By comparing the rate of reaction of the two fluids with Indiana limestone at different RPM, the overall reaction of GLDA with the rock surface is inhibited with the presence of salt ions from seawater in the GLDA/SW solution. In addition, multivalent cations affect the diffusion coefficient. It has been proved that both $\mathrm{Mg}^{2+}$ and $\mathrm{Ca}^{2+}$ affect the $\mathrm{H}^{+}$diffusion and will retard the reaction rate, which will enforce deep acid penetration as follows [15]:

$$
D_{\left(H^{+}\right)}=\operatorname{EXP}\left\{\begin{array}{c}
\left(\frac{2918.54}{T}\right)-0.589 \sqrt{\frac{\left[\mathrm{Ca}^{2+}\right]}{\left[\mathrm{H}^{+}\right]}} \\
-0.789 \sqrt{\frac{\left[\mathrm{Mg} \mathrm{g}^{2+}\right]}{\left[\mathrm{H}^{+}\right]}}+0.452\left[\mathrm{H}^{+}\right]-4.995
\end{array}\right\}
$$

$\mathrm{Mg}^{2+}$ and $\mathrm{Ca}^{2+}$ will retard the reaction in two ways; the first one is according to the previous equation and the second one is that both $\mathrm{Mg}^{2+}$ and $\mathrm{Ca}^{2+}$ will increase the GLDA viscosity and this will reduce the acid diffusion.

The scanning electron microscopy (SEM) images for the Indiana limestone samples from experiments at same RPM showed that GLDA/DI mainly reacted only with fine grains in the rock surface while GLDA/SW reacted with both fine and coarse grains and made the reaction more uniform at the rock surface (Figure 9). Decreasing the acid diffusion hinders the acid spending process and allows fresh acid to deeply penetrate the rock matrix more uniformly. Based on this, GLDA/SW system can stimulate cores in less injected acid volume at lower injection rate compared to GLDA/DI system. A coreflooding study is required to validate this conclusion. 


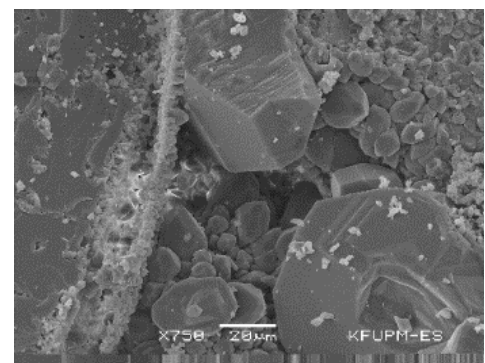

(a) Before Reaction

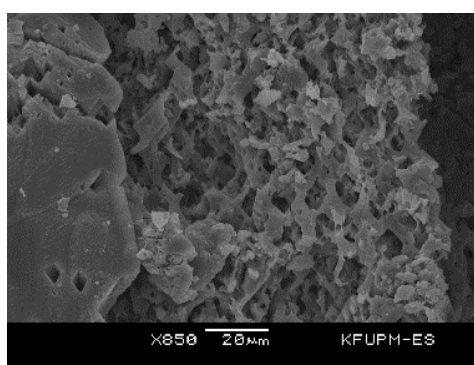

(b) After Reaction with GLDA/DI

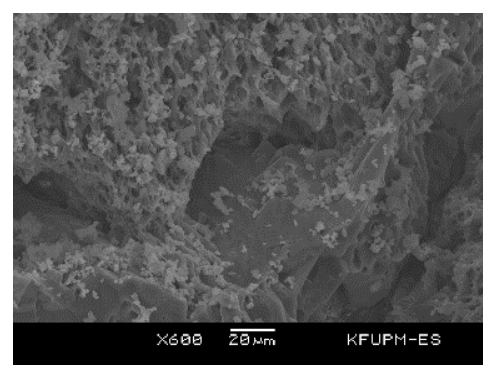

(c)After Reaction with GLDA/SW

Figure 9. SEM surface morphology of Indiana limestone rock surface (a) before reaction; (b) after reaction with GLDA/DI; and (c) after reaction with GLDA/SW acid systems at $200^{\circ} \mathrm{F}$ and $1000 \mathrm{RPM}$.

\subsection{Austin Chalk}

Four experiments were carried out using Austin chalk samples at $200^{\circ} \mathrm{F}$ in the same way described at similar conditions to Indiana limestone sample using GLDA/SW fluid system. The results are shown in Figure 10. From the behavior of the reaction rate versus the square root of the disk angular velocity, it is clear that the reaction regime is mass transfer limited with a reaction diffusion coefficient of $3.96 \times 10^{-5} \mathrm{~cm}^{2} / \mathrm{s}$. The measured diffusion coefficient is higher for Austin chalk case. It's almost an order of magnitude higher than the diffusion coefficient in the case of reaction with Indiana limestone at the same conditions. With the fact that both Indiana limestone and Austin chalk are chemically composed of almost $100 \%$ calcium carbonate, the difference in reaction rates (Figure 11) can be attributed to the pore system geometry and to the bond between the rock grains. The unconfined compressive strength of Indiana limestone is about $5000 \mathrm{psi}$ compared to about $3000 \mathrm{psi}$ in case of Austin chalk. The chelating agent leached more calcite from the Austin chalk samples than the Indiana limestone samples. This effect cannot be captured if only marble was used.

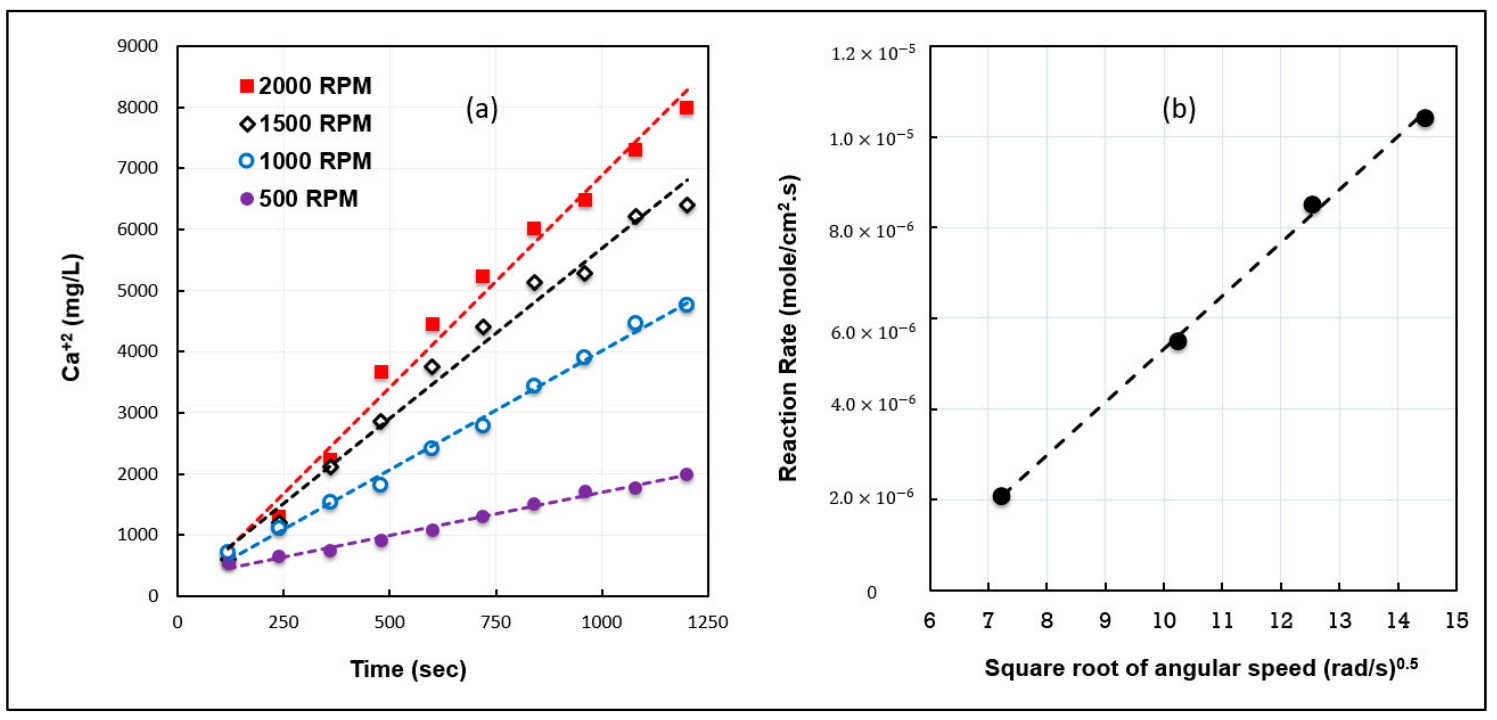

Figure 10. (a) The concentration of calcium in the collected fluid samples as a function of time and rotation speed using $20 \mathrm{wt} \%$ GLDA/SW solution with Austin chalk disks at $200{ }^{\circ} \mathrm{F}$; (b) the Rate of calcite dissolution in $20 \mathrm{wt} \% \mathrm{GLDA} /$ seawater at $\mathrm{pH}$ of 3.8 at $1000 \mathrm{psi}$ and $200{ }^{\circ} \mathrm{F}$. 


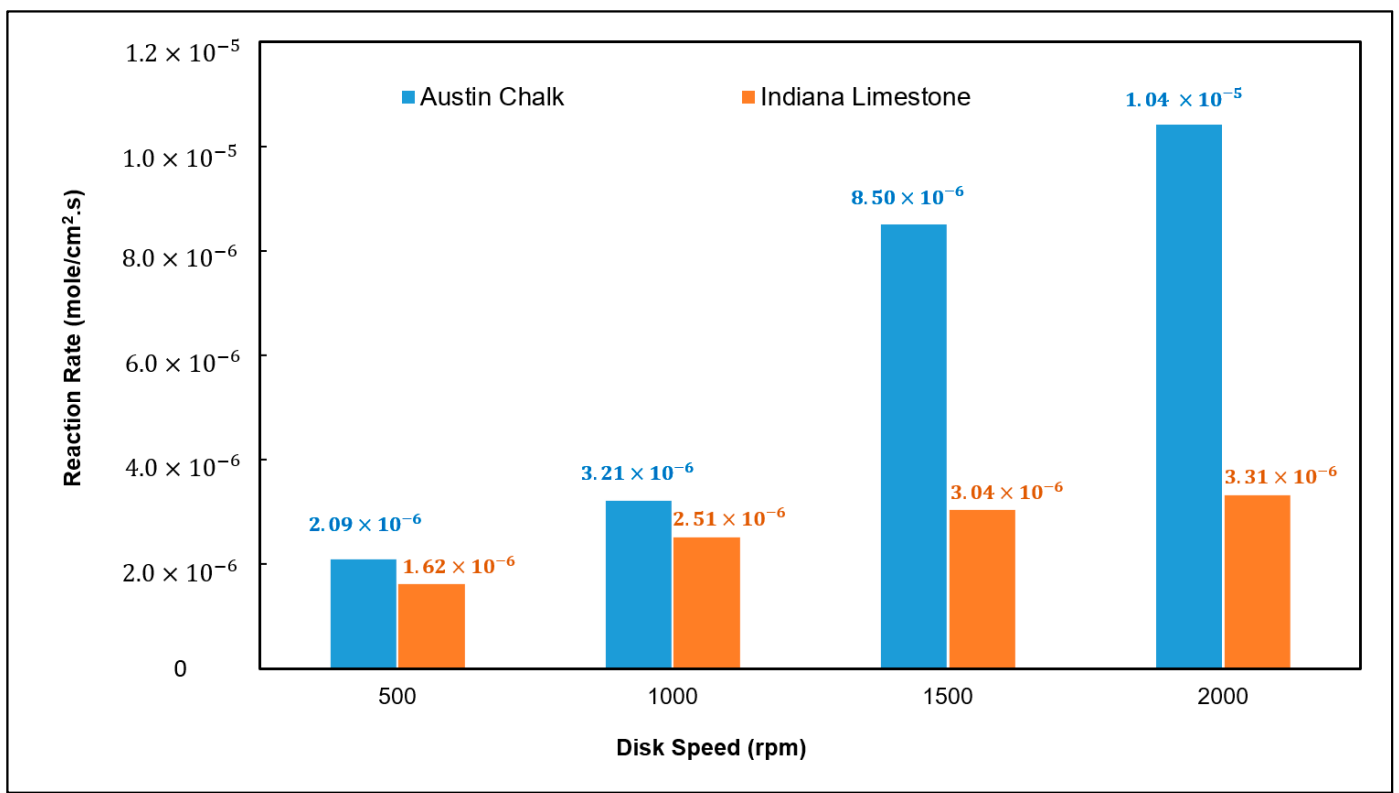

Figure 11. Reaction rated of GLDA/seawater with Austin chalk and Indiana limestone at $200^{\circ} \mathrm{F}$ and 1000 psi.

Contrast resulted from different atomic number elements and their distribution is displayed by scanning electron microscopy (SEM). The effect of the acid system on the surface morphology of Austin chalk and Indiana limestone carbonate rocks used in this study is shown in Figure 12.

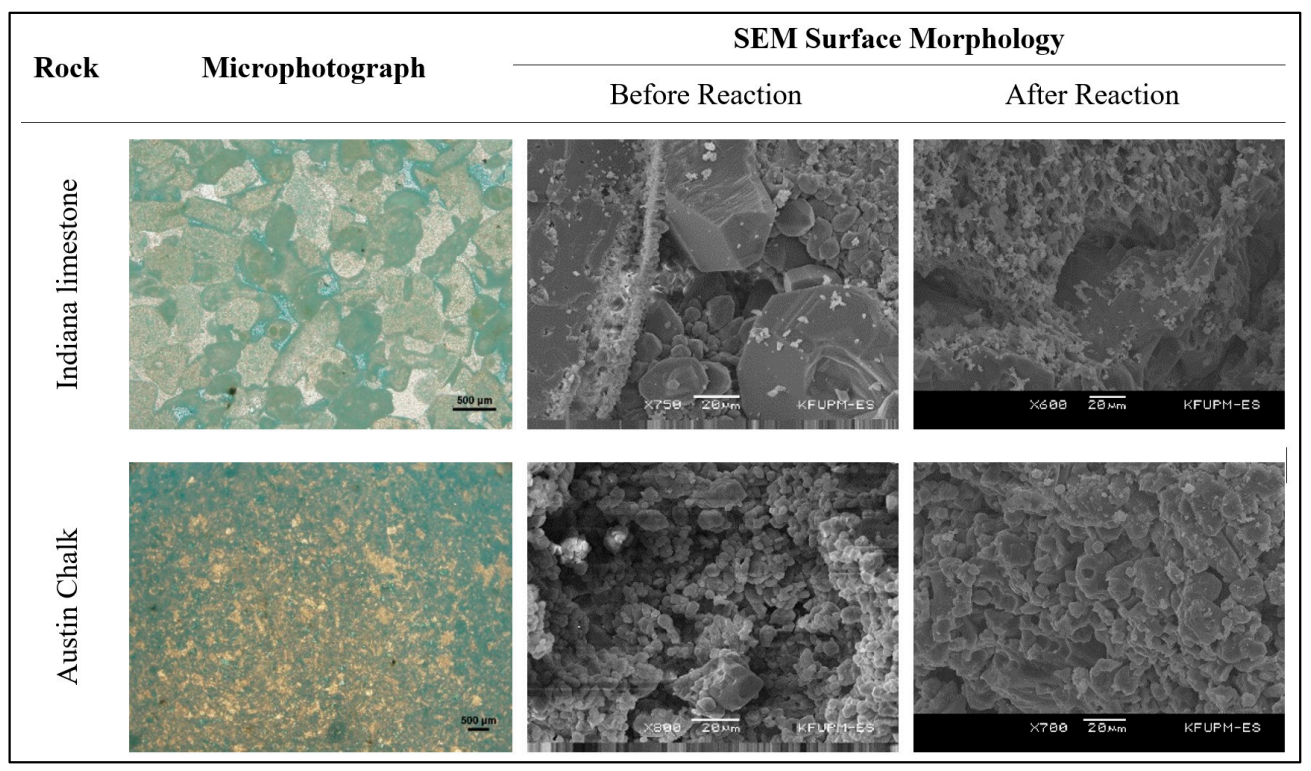

Figure 12. SEM and Microphotograph for a thin section of Indiana limestone and Austin chalk before and after reaction with GLDA/SW system at $200^{\circ} \mathrm{F}$ and $1000 \mathrm{RPM}$.

Indiana limestone, as a bioclastic coarse grained, cemented, and mechanically compacted calcite rock, is less reactive than the microgranular fine grained Austin chalk. Thus, it is clear that each calcite rock has to be studied for the reaction kinetics for the selected stimulation fluid. Marble results will not be applicable for other calcite rocks with the same porosity and permeability. It was observed that not only Damkholer and Peclet numbers control the reactions, but also the rock facies (porosity type and strength) play a major role. All the diffusion rates are listed in Table 4 as a summary for the rotating disc experiments. 
Table 4. Diffusion rates from the RDA experiments using GLDA with Indiana limestone and Austin chalk calcite roks.

\begin{tabular}{|c|c|c|}
\hline Fluid/Rock & $\begin{array}{l}\text { Temperature } \\
\left({ }^{\circ} \mathbf{F}\right)\end{array}$ & $\begin{array}{c}\text { Diffusion Rates } \\
\left(\mathrm{cm}^{2} / \mathrm{s}\right)\end{array}$ \\
\hline \multirow{3}{*}{$\begin{array}{c}20 w \mathrm{t} \% \\
\text { GLDA/DI/Indiana limestone }\end{array}$} & 150 & - \\
\hline & 200 & $4.59 \times 10^{-6}$ \\
\hline & 250 & $1.07 \times 10^{-5}$ \\
\hline \multirow{3}{*}{$\begin{array}{c}20 \mathrm{wt} \% \\
\text { GLDA/SW/Indiana limestone }\end{array}$} & 150 & $8.31 \times 10^{-7}$ \\
\hline & 200 & $3.37 \times 10^{-6}$ \\
\hline & 250 & $4.71 \times 10^{-6}$ \\
\hline $\begin{array}{c}20 \mathrm{wt} \% \\
\text { GLDA/SW/Austin chalk }\end{array}$ & 200 & $3.96 \times 10^{-5}$ \\
\hline
\end{tabular}

\subsection{Coreflooding Experiments}

To estimate the optimum injection rate using GLDA/SW system, several linear corefloods were performed using $3.81 \mathrm{~cm}$ (1.5-inch) diameter and $15.24 \mathrm{~cm}$ (6-inch) long Indiana limestone samples. Table 5 shows the experimental parameters and flooding conditions while Figure 13 shows the schematic of the coreflooding set-up used to carry out linear corefloods at reservoir conditions. The coreflooding system used is a multi purpose EOR flooding systems assembled by Vinci, Nanterre, France.



Figure 13. Schematic of the linear coreflooding system.

Table 5. Routine properties of the core samples used for coreflooding at $250{ }^{\circ} \mathrm{F}$ and 1000 psi back pressure at different injection rates $(\mathrm{Q})$.

\begin{tabular}{ccccccc}
\hline Experiment & $\begin{array}{c}\mathbf{L} \\
\mathbf{( c m )}\end{array}$ & $\begin{array}{c}\mathbf{D} \\
\mathbf{( c m )}\end{array}$ & $\begin{array}{c}\mathbf{\phi} \\
\mathbf{( \% )}\end{array}$ & $\begin{array}{c}\mathbf{P V} \\
\left(\mathbf{c m}^{\mathbf{3}}\right)\end{array}$ & $\begin{array}{c}\mathbf{K} \\
(\mathbf{m D})\end{array}$ & $\begin{array}{c}\mathbf{Q} \\
\left(\mathbf{c m}^{3} \mathbf{m i n}\right)\end{array}$ \\
\hline 1 & 14.94 & 3.81 & 9.17 & 15.61 & 0.30 & 0.25 \\
2 & 15.09 & 3.81 & 8.30 & 14.30 & 0.51 & 0.5 \\
3 & 15.02 & 3.81 & 10.54 & 18.06 & 1.86 & 1.0 \\
4 & 15.03 & 3.81 & 9.55 & 16.37 & 0.75 & 2.0 \\
5 & 15.17 & 3.81 & 9.51 & 16.46 & 0.81 & 3.0 \\
\hline
\end{tabular}

(L) sample length, (D) sample diameter, $(\phi)$ porosity, $(\mathrm{PV})$ pore volume, K permeability, $(\mathrm{Q})$ flow rate. 
For all the experiments, $3 \mathrm{wt} \% \mathrm{KCl}$ (potassium chloride) was used to measure liquid permeability at room temperature, then the temperature was increased to $250^{\circ} \mathrm{F}$ for six hours to allow temperature equilibration inside the core sample. The desired injection rate was then set $(0.25,0.5,1.0,2.0$, or $3.0 \mathrm{~cm}^{3} / \mathrm{min}$ ). Once a steady state flow is achieved by having a constant pressure drop between the inlet and the outlet of the core holder, the injected fluid is switched to GLDA/SW. For each coreflood, the injected acid volume is reported in pore volumes at the wormhole breakthrough ( $\mathrm{PV}_{\mathrm{BT}}$ ) corresponding to zero value of the pressure drop indicating the creation of an infinite conductive channel (wormhole) through the rock sample (Figures 14 and 15). From the CT-scans of the rock samples, a dominant wormhole can be seen at injection rates of 0.5 and $1.0 \mathrm{~cm}^{3} / \mathrm{min}$. A wider wormhole can be seen at $2.0 \mathrm{~cm}^{3} / \mathrm{min}$ compared to lower injection rates with more acid volume required to breakthrough. On the other hand, at 3 and $4 \mathrm{~cm}^{3} / \mathrm{min}$ several wormholes were initiated at the face of the rock but only a single wormhole propagates with acid injection through the entire rock sample. Unlike $\mathrm{HCl}$, one cannot define a sharp optimum concentration for GLDA. Instead, an optimum injection rate range can be defined between 0.5 and $1 \mathrm{~cm}^{3} / \mathrm{min}$. Comparing the pore volumes of $20 \mathrm{wt} \%$ GLDA/SW required to breakthrough obtained in this study with the coreflooding using 20wt\% GLDA/DI [28], it is clear that the seawater had a retarding effect on GLDA which requires more PV to breakthrough in presence of seawater. The retardation effect is very effective at low injection rate where the retention time of the acid inside the rock is high. Thus, there are two competing mechanisms: the first one is the retardation effect by salts and the second one is the injection rate. At higher injection rate, the acid restricted diffusion (due to salts) will lower the GLDA dissolution capacity and in turn, more acid volume is consumed to create the wormhole. While At low injection rates, GLDA will have enough contact time with the rock in addition to retardation effect and this will result in smooth, tiny wormholes.



Figure 14. The breakthrough curve of $20 \mathrm{wt} \% \mathrm{GLDA} / \mathrm{SW}$ ( $\mathrm{pH} 3.8$ ) in six inches. Indiana limestone core samples at $250^{\circ} \mathrm{F}$ compared to GLDA/DI at $\mathrm{pH}$ of 3.8 in 6.0 inches by Mahmoud et al. (2011). 




Figure 15. Pressure drop as a function of injected pore volumes during injection of $20 \mathrm{wt} \% \mathrm{GLDA} / \mathrm{SW}$ $(\mathrm{pH}=3.8)$ at $250^{\circ} \mathrm{F}$ at different injection rates.

The pore volumes of $20 \mathrm{wt} \%$ GLDA/DI consumed to achieve breakthrough at $0.25 \mathrm{~cm}^{3} / \mathrm{min}$ is almost twice the consumed volume of $20 \mathrm{wt} \%$ GLDA/SW at the same rate (Figure 16).

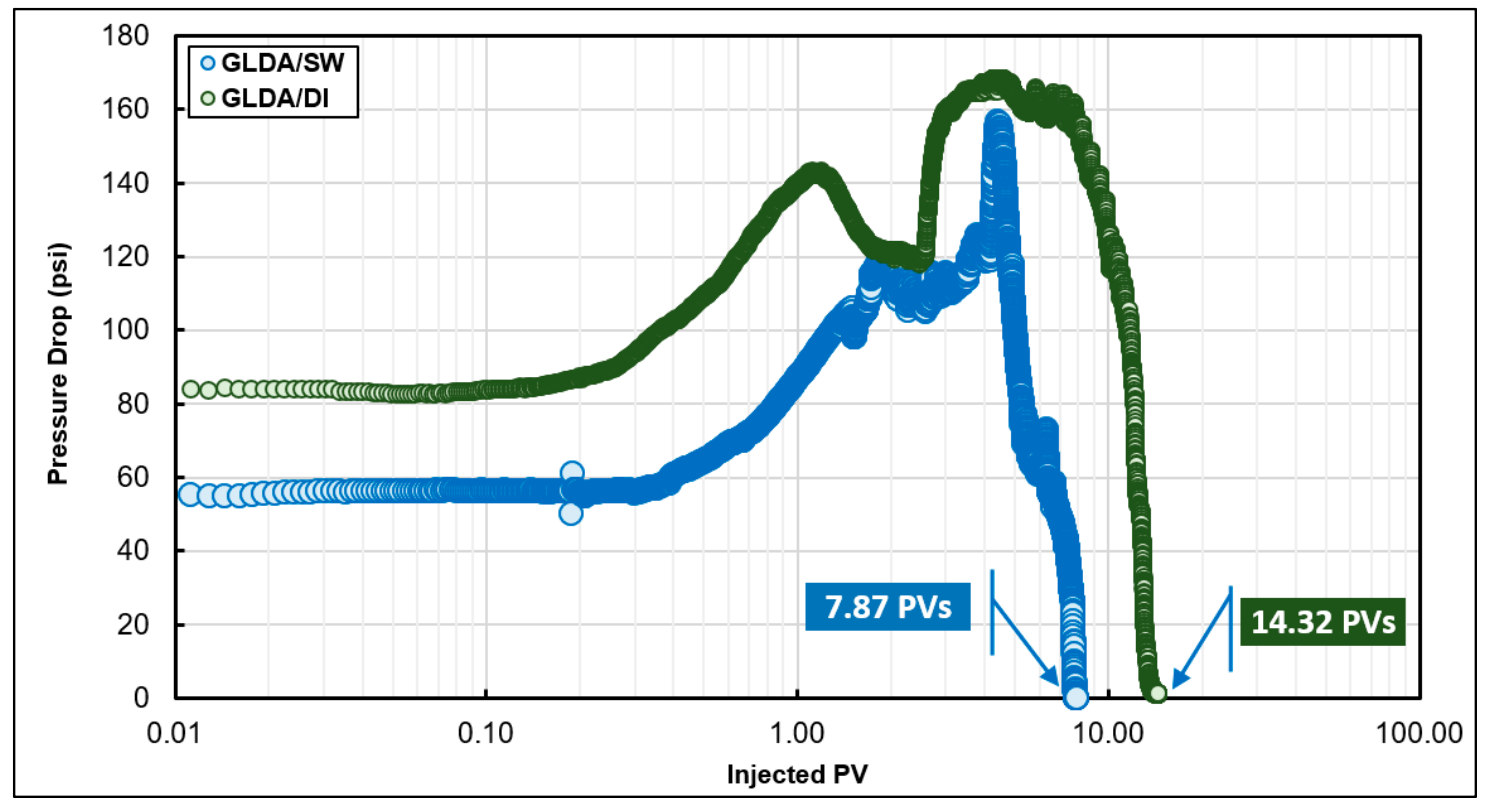

Figure 16. Pressure drop variation during injection of $20 \mathrm{wt} \% \mathrm{GLDA} / \mathrm{SW}(\mathrm{pH}=3.8)$ at $250{ }^{\circ} \mathrm{F}$ at $0.25 \mathrm{~cm}^{3} / \mathrm{min}$ compared to $20 \mathrm{wt} \%$ GLDA/DI at $\mathrm{pH}$ of 3.8 in 6.0 inches of Indiana limestone.

An X-ray computed tomography (CT) scanner was used to characterize the wormholes at an energy of $135 \mathrm{~kW} / 200 \mathrm{~mA}$ and $1.0 \mathrm{~mm}$ resolution (Figure 17). For $20 \mathrm{wt} \% \mathrm{GLDA} / \mathrm{SW}$, the optimum injection rate is between 0.5 and $1.0 \mathrm{~cm}^{3} / \mathrm{min}$ with thin, less ramified wormholes at minimum pore volumes (PVs) required to breakthrough. 


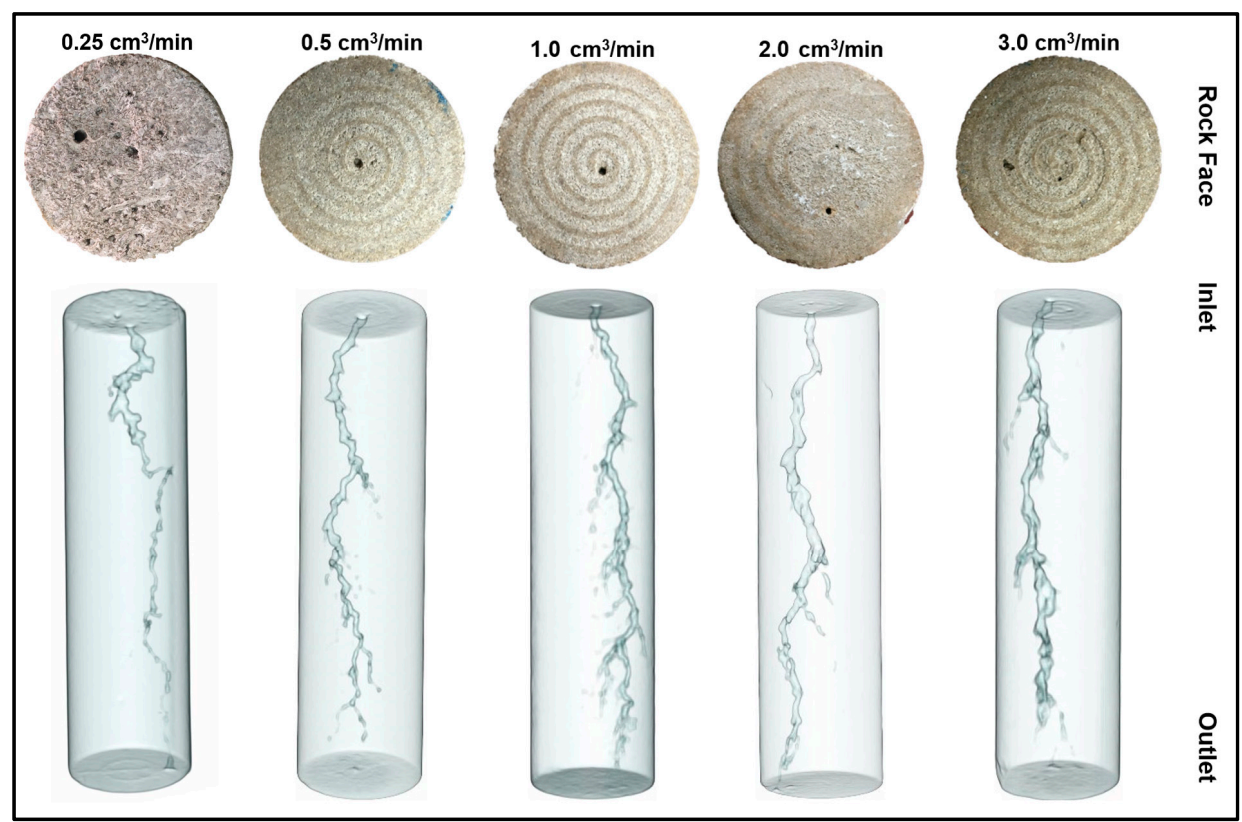

Figure 17. Wormhole structure using CT scan for core samples stimulated using $20 \mathrm{wt} \%$ GLDA/SW $(\mathrm{pH}=3.8)$ at $250^{\circ} \mathrm{F}$.

For accurate determination of GLDA optimum injection rate, a normalized pressure drop ratio (PDR) defined by Equation (9) is used. At the optimum injection rate, the minimum injected pore volume is used during the wormhole propagation to achieve the maximum value of pressure drop reduction from the maximum pressure drop encountered during the acid injection. PDR at time $t_{i}$ is defined as:

$$
P D R_{i}=\frac{\Delta p_{\max }-\Delta p_{i}}{\Delta p_{\max }}
$$

where $\Delta p_{\max }$ is the maximum pressure drop for each injection rate, $\Delta p_{i}$ is the pressure drop achieved at time $t_{\mathrm{i}}$. For example, as shown in Figure 18, at an injection rate of $0.5 \mathrm{~cm}^{3} / \mathrm{min}$ about $2.0 \mathrm{PVs}$ achieved $60 \%$ reduction of $\Delta p_{\max }$ where $3.0 \mathrm{PVs}$ were required to achieve the same pressure drop reduction at $1.0 \mathrm{~cm}^{3} / \mathrm{min}$ injection rate, $5.0 \mathrm{PVs}$ at $2.0 \mathrm{~cm}^{3} / \mathrm{min}$ and $6.0 \mathrm{PVs}$ at $3.0 \mathrm{~cm}^{3} / \mathrm{min}$. Based on this, $0.5 \mathrm{~cm}^{3} / \mathrm{min}$ can be selected as the optimum injection rate because of the earlier achieved PDR at minimum injected PVs compared to other injection rates.

Using the optimum injection rate model to determine the linear optimum injection rate as a function of core length and diffusion coefficient as follows [45]:

$$
Q_{o p t} L=102 h_{f} L_{\text {core }} D_{e}
$$

where $h_{f}$ is the heterogeneity factor, which is defined as the ratio of wormhole length to core length, $L_{\text {core }}$ is the core length, $\mathrm{cm}$, and $D_{e}$ is the diffusion coefficient, $\mathrm{cm}^{2} / \mathrm{s}$. For a 6-inches core sample, and $4.71 \times 10^{-6} \mathrm{~cm}^{2} / \mathrm{s}$ diffusion coefficient, an optimum injection rate of $0.43 \mathrm{~cm}^{3} / \mathrm{min}$ is calculated compared to $0.5 \mathrm{~cm}^{3} / \mathrm{min}$ as obtained from the coreflooding analysis. Based on this, the results of the rotating disk can be extrapolated to different temperature conditions and the optimum injection rate as a function of temperature and core length can be drawn (Figure 19). Figure 19 represents a graphical representation for Equation (10) for 1.5-inches dimeter Indiana limestone and $20 \mathrm{wt} \%$ GLDA/SW ( $\mathrm{pH} 3.8$ ) as a function of temperature. For example, if $20 \mathrm{wt} \% \mathrm{GLDA} / \mathrm{SW}$ is to be used to generate the optimum wormhole at $300^{\circ} \mathrm{F}$ through a 1.5-inch diameter and 12-inch long rock sample, an injection rate of 1.3 is to be used for that purpose. 


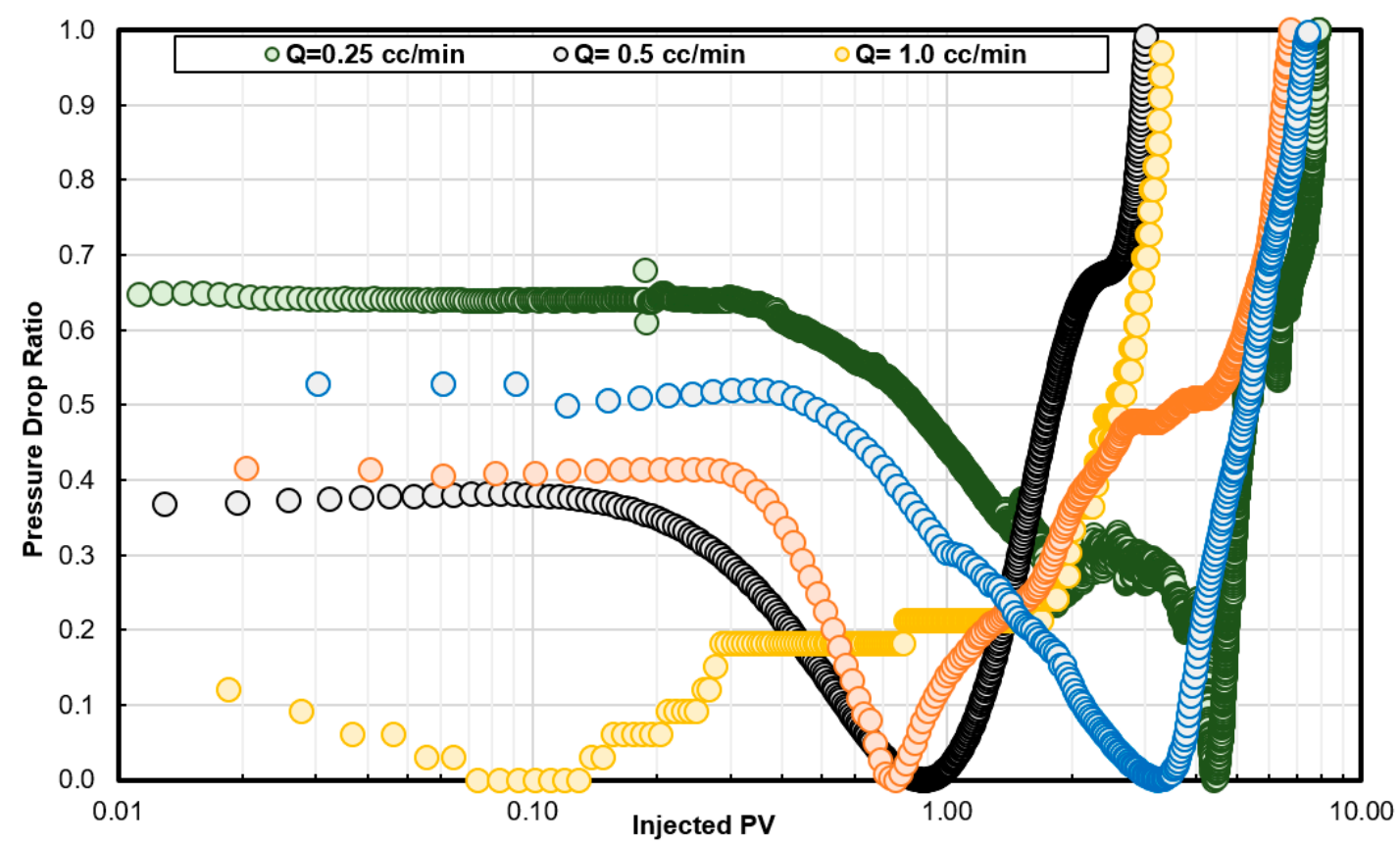

Figure 18. Normalized pressure drop as a function of injected pore volumes during injection of $20 \mathrm{wt} \%$ GLDA/SW $(\mathrm{pH}=3.8)$ at $250^{\circ} \mathrm{F}$.

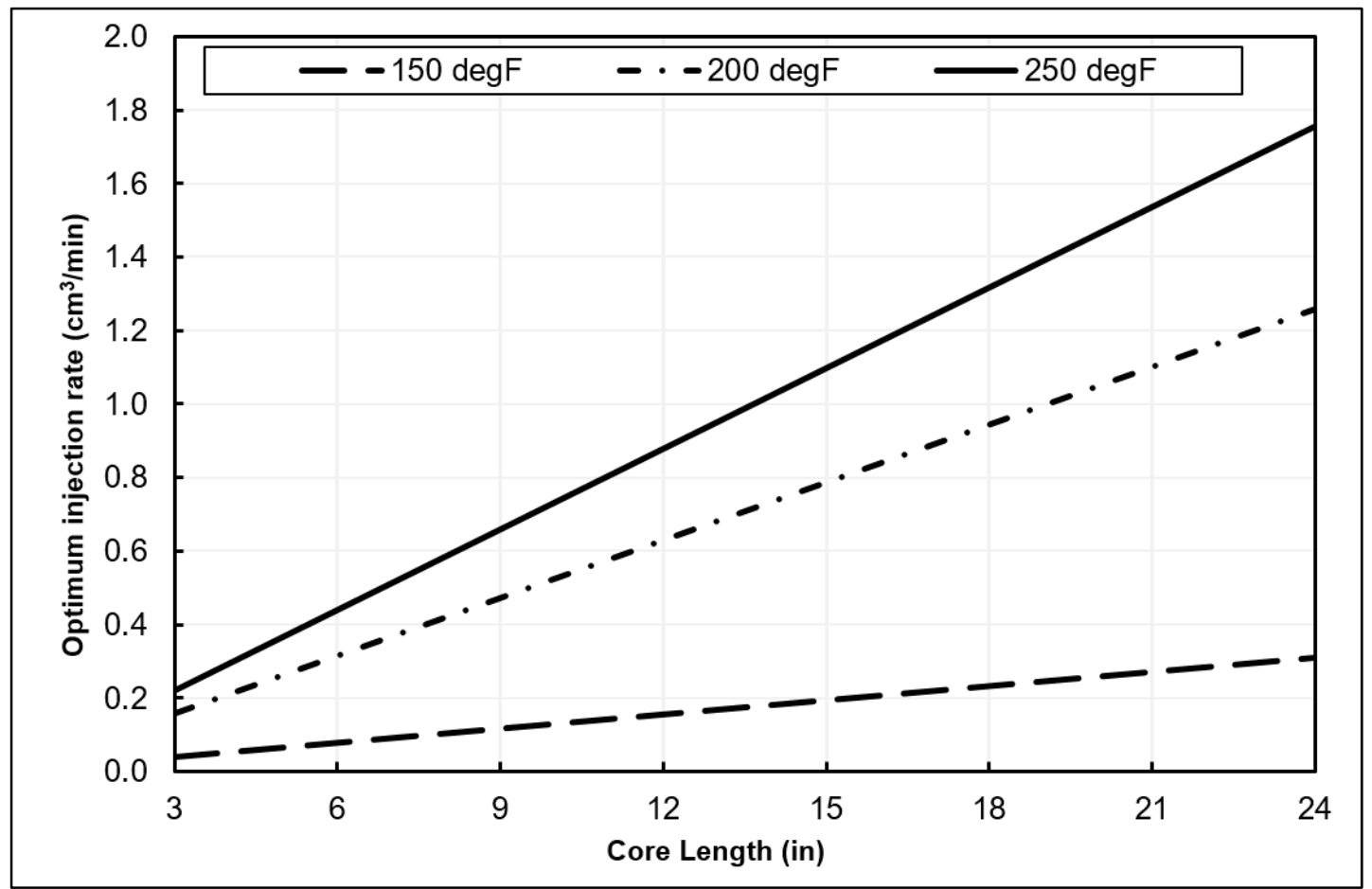

Figure 19. The optimum injection rate of $20 \mathrm{wt} \% \mathrm{GLDA} / \mathrm{SW}$ at $\mathrm{pH} 3.8$ as a function of temperature and core length.

\section{Conclusions}

In this study, the use of seawater as a base for GLDA chelating agent was proved to be efficient for carbonate stimulation. The reaction of the GLDA/seawater was investigated and the following can be concluded from this study: 
- Rock facies (porosity type) as well as rock strength highly affected the reaction kinetics of GLDA with calcite. This means that the kinetics for each reservoir rock should be investigated with the stimulation fluid. The two tested rocks in this study (Indiana limestone and Austin chalk) are almost $100 \%$ calcite but they behaved differently at the same conditions of reaction experiments.

- Using seawater to prepare GLDA did not affect the reaction regime at 200 and $250^{\circ} \mathrm{F}$. The reaction regime is limited by mass transfer for both seawater and deionized water based GLDA.

- The salt content in seawater retarded the reaction when seawater was used as a base for GLDA. The effect was minor at $200^{\circ} \mathrm{F}$ and it was prominent at $250{ }^{\circ} \mathrm{F}$. At $250^{\circ} \mathrm{F}$, the GLDA/seawater diffusion coefficient is $50 \%$ that in the case of GLDA/deionized water. This is considered as a positive point in the case of GLDA/seawater because it will achieve deep acid penetration due to the retardation effect of the salt in the seawater.

- A new approach based on dimensionless pore volume to breakthrough, dimensionless time to breakthrough, and the pressure drop ratio was introduced to determine the optimum injection rate in the case of GLDA/seawater stimulation fluid. Unlike $\mathrm{HCl}$ and other stimulation fluid, GLDA does not have a sharp optimum injection rate. GLDA has a range for optimum injection rate and the best one can be determined based on the new approach introduced in this study.

- This study reveals that the rotating disk reaction experiments can be used instead of coreflooding experiments to predict the optimum injection rate in the case of stimulation fluids of mass transfer limited reaction regime.

- To include the effect of damage length or core length during the coreflooding experiments, more coreflooding experiments are required while a single diffusion coefficient can be used to define the optimum injection rate as a function of core length, which makes the rotating disk approach more convenient in most of the cases. For example, the optimum injection rate predicted from coreflooding was $0.5 \mathrm{~cm}^{3} / \mathrm{min}$ and that from the rotating disk experiments was $0.43 \mathrm{~cm}^{3} / \mathrm{min}$.

Author Contributions: Conceptualization, methodology, and validation, K.Z.A. and M.M.; formal analysis, K.Z.A.; investigation, S.E.; resources, M.M.; writing—original draft preparation, K.Z.A.; writing一review and editing, M.M., S.E. and A.A.; visualization, K.Z.A. and S.E.; supervision, M.M.; project administration, M.M.; funding acquisition, S.P.

Funding: This research was funded by The College of Petroleum Engineering and Geoscinces at King Fahd Univeristy of Petroleum \& Minerls.

Acknowledgments: The authors are very thankful to the College of Petroleum Engineering and Geosciences (CPG), King Fahd University of Petroleum and Minerals (KFUPM), for providing financial support to this word. We are also thankful to staff members of the center of integrated petroleum research for allowing us to use the facilities in CIPR Analytical chemistry and advance fluids laboratories.

Conflicts of Interest: The authors declare no conflict of interest.

\section{References}

1. Williams, B.; Gidley, J.; Schechter, R. Acidizing Fundamentals; SPE Monograph Series; Henry L. Doherty Memorial Fund of AIME, Society of Petroleum Engineers of AIME: Richardson, TX, USA, 1979.

2. Daccord, G. Chemical dissolution of a porous medium by a reactive fluid. Phys. Rev. Lett. 1987, 58, 479-482. [CrossRef] [PubMed]

3. Hoefner, M.L.; Fogler, H.S. Pore evolution and channel formation during flow and reaction in porous media. AIChE J. 1988, 34, 45-54. [CrossRef]

4. Wang, Y.; Hill, A.D.; Schechter, R.S. The Optimum Injection Rate for Matrix Acidizing of Carbonate Formations. In Proceedings of the SPE Annual Technical Conference and Exhibition, Houston, TX, USA, 3-6 October 1993. [CrossRef]

5. Daccord, G.; Liétard, O.; Lenormand, R. Chemical dissolution of a porous medium by a reactive fluid-II. Convection vs. reaction, behavior diagram. Chem. Eng. Sci. 1993, 48, 179-186. [CrossRef]

6. Fredd, C.N.; Fogler, H.S. Influence of transport and reaction on wormhole formation in carbonate porous media. AIChE J. 1998, 44, 1933-1949. [CrossRef] 
7. Bazin, B. From matrix acidizing to acid fracturing: A laboratory evaluation of acid/rock interactions. SPE Prod. Facil. 2001, 16, 22-29. [CrossRef]

8. Fredd, C.N.; Miller, M. Validation of carbonate matrix stimulation models. In Proceedings of the SPE International Symposium on Formation Damage Control, Lafayette, LA, USA, 23-24 February 2000. [CrossRef]

9. Golfier, F.; Zarcone, C.; Bazin, B.; Lenormand, R.; Lasseux, D.; Quintard, M. On the ability of a Darcy-scale model to capture wormhole formation during the dissolution of a porous medium. J. Fluid Mech. 2002, 475, 213-254. [CrossRef]

10. Glasbergen, G.; Kalia, N.; Talbot, M.S. The Optimum Injection Rate for Wormhole Propagation: Myth or Reality? In Proceedings of the 8th European Formation Damage Conference, Scheveningen, The Netherlands, 27-29 May 2009. [CrossRef]

11. Maheshwari, P.; Balakotaiah, V. Comparison of Carbonate $\mathrm{HCl}$ Acidizing Experiments with 3D Simulations. SPE Prod. Oper. 2013, 28, 402-413. [CrossRef]

12. Fredd, C.N. The Influence of Transport and Reaction on Wormhole Formation in Carbonate Porous Media: A Study of Alternative Stimulation Fluids. Ph.D. Thesis, University of Michigan, Ann Arbor, MI, USA, 1998. Available online: http://hdl.handle.net/2027.42/130957 (accessed on 15 June 2017).

13. Darren, M.; Shuchart, C.; Jackson, S.; Postl, D.; Brown, J.S. Understanding Wormholes in Carbonates: Unprecedented Experimental Scale and 3D Visualization. J. Pet. Technol. 2010, 62, 78-81. [CrossRef]

14. Nierode, D.E.; Williams, B.B. Characteristics of Acid Reaction in Limestone Formations. SPE J. 1971, 11, 406-418. [CrossRef]

15. Mahmoud, M.; Al-Duailej, Y.; Al-Khaldi, M.; Kwak, H.; Shebatalhamd, A.; Al-Yami, I. NMR as a Characterization Tool for Wormholes. SPE Prod. Oper. 2016, 31, 362-373. [CrossRef]

16. Conway, M.W.; Asadi, M.; Penny, G.S.; Chang, F. A Comparative Study of Straight/Gelled/Emulsified Hydrochloric Acid Diffusivity Coefficient Using Diaphragm Cell and Rotating Disk. In Proceedings of the SPE Annual Technical Conference and Exhibition, Houston, TX, USA, 3-6 October 1999. [CrossRef]

17. Dwyer, F.P.J.; Mellor, D.P. Chelating Agents and Metal Chelates; Academic Press Inc.: New York, NY, USA, 1964. [CrossRef]

18. Crabetree, M.; Eslinger, D.; Fletcher, P.; Miller, M.; Johnson, A.; King, G. Fighting scale-removal and prevention. Schlumberger Oil Field Rev. 1999, 11, 30-45.

19. Tomson, M.B.; Fu, G.; Watson, M.A.; Kan, A.T. Mechanisms of Mineral Scale Inhibition. SPE Prod. Facil. 2003, 18, 192-199. [CrossRef]

20. Mahmoud, M.; Abdelgawad, K.Z.; Elkatatny, S.M.; Akram, A.; Stanitzek, T. Stimulation of Seawater Injectors by GLDA (Glutamic-Di Acetic Acid). SPE Drill. Compl. 2016, 31, 178-187. [CrossRef]

21. Ba-geri, B.; Mahmoud, M.; Abdulraheem, A.; Al-Mutairi, S.; Elkatatny, S.; Shawabkeh, A. Single stage filter cake removal of barite-weighted water based drilling fluid. J. Pet. Sci. Eng. 2017, 149, 476-484. [CrossRef]

22. Mahmoud, M.A.; Abdelgawad, K.Z. Chelating-Agent Enhanced Oil Recovery for Sandstone and Carbonate Reservoirs. SPE J. 2015, 20, 483-495. [CrossRef]

23. Attia, M.; Mahmoud, M.A.; Al-Hashim, H.S.; Sultan, A.S. Shifting to a New EOR Area for Sandstone Reservoirs with High Recovery, No Damage, and Low Cost. In Proceedings of the SPE EOR Conference at Oil and Gas West Asia, Muscat, Oman, 31 March-2 April 2014. [CrossRef]

24. Frenier, W.W.; Fredd, C.N.; Chang, F. Hydroxyaminocarboxylic Acids Produce Superior Formulations for Matrix Stimulation of Carbonates. In Proceedings of the European Formation Damage Conference, The Hague, The Netherlands, 21-22 May 2001. [CrossRef]

25. Frenier, W.W.; Rainey, M.; Wilson, D.; Crump, D.; Jones, L. A Biodegradable Chelating Agent is Developed for Stimulation of Oil and Gas Formations. In Proceedings of the SPE/EPA/DOE Exploration and Production Environmental Conference, San Antonio, TX, USA, 10-12 March 2003. [CrossRef]

26. De Wolf, C.A.; Nasr-El-Din, H.A.; Bouwman, A.; Bang, E.R.A.; Naylor, E. Corrosion rates of Cr- and Ni-based alloys with organic acids and chelating agents used in stimulation of deep wells. SPE Prod. Oper. 2017, 32, 208-217. [CrossRef]

27. LePage, J.N.; De Wolf, C.; Bemelaar, J.; Nasr-El-Din, H.A. An Environmentally Friendly Stimulation Fluid for High-Temperature Applications. Society of Petroleum Engineers. In Proceedings of the SPE International Symposium on Oilfield Chemistry, The Woodlands, TX, USA, 20-22 April 2009. [CrossRef] 
28. Mahmoud, M.A.; Nasr-El-Din, H.A.; De Wolf, C.; LePage, J.; Bemelaar, J. Evaluation of a New Environmentally Friendly Chelating Agent for High-Temperature Applications. SPE J. 2011, 16, 559-574. [CrossRef]

29. Nasr-El-Din, H.A.; Dana, H.; Tomos, V.; Stanitzek, T.; de Wolf, C.A.; Alex, A. Field Treatment to Stimulate an Oil Well in an Offshore Sandstone Reservoir Using a Novel, Low Corrosive, Environmentally Friendly Fluid. In Proceedings of the SPE International Symposium and Exhibition on Formation Damage Control, Lafayette, LA, USA, 26-28 February 2014. Paper SPE-168163-MS. [CrossRef]

30. Barri, A. Identifying Optimum Conditions for Stable Wormholes Created by Chelating Agents. Master's Thesis, King Fahd University of Petroleum and Minerals, Dhahran, Saudi Arabia, 2015. Available online: http://eprints.kfupm.edu.sa/139626/ (accessed on 15 June 2017).

31. Begum, Z.; Rahman, I.; Tate, Y.; Egawa, Y.; Maki, T.; Hasegawa, H. Formation and stability of binary complexes of divalent ecotoxic ions ( $\mathrm{Ni}, \mathrm{Cu}, \mathrm{Zn}, \mathrm{Cd}, \mathrm{Pb}$ ) with biodegradable aminopolycarboxylate chelants (DL-2-(2- carboxymethyl)nitrilotriacetic acid, GLDA, and 3-hydroxy-2,20-iminodisuccinic acid, HIDS) in aqueous solutions. J. Solut. Chem. 2012, 41, 1713-1728. [CrossRef]

32. Mahmoud, M.A.; Nasr-El-Din, H.A.; LePage, J.N.; De Wolf, C. Optimum Injection Rate of a New Chelate That Can Be Used to Stimulate Carbonate Reservoirs. SPE J. 2011, 16, 968-980. [CrossRef]

33. Nasr-El-Din, H.A.; de Wolf, C.A.; Stanitzek, T.; Alex, A.K.; Gerdes, S.; Lummer, N.R. Field Treatment to Stimulate a Deep, Sour, Tight-Gas Well Using a New, Low Corrosion and Environmentally Friendly Fluid. SPE Prod. Oper. 2013, 28, 277-285. [CrossRef]

34. Nuñez, W.; Bautista, O.; Cepeda, F.A.; Kleber, M.A.; Dos Santos, A.A.; Oliveira, E.; Rodriguez, O. Field Treatment of an Injector Well in a Sandstone Formation Using a Low Corrosive Environmentally Friendly Fluid that Does Not Require Flow-Back. In Proceedings of the SPE Latin America and Caribbean Petroleum Engineering Conference, Buenos Aires, Argentina, 17-19 May 2017. [CrossRef]

35. Ameur, Z.O.; Kudrashou, V.Y.; Nasr-El-Din, H.A.; Forsyth, J.P.J.; Mahoney, J.J.; Daigle, B.J. Stimulation of High Temperature SAGD Producer Wells Using a Novel Chelating Agent (GLDA) and Subsequent Geochemical Modeling Using PHREEQC. In Proceedings of the SPE International Symposium on Oilfield Chemistry, The Woodlands, TX, USA, 13-15 April 2015. [CrossRef]

36. Klaewkla, R.; Arend, M.; Hoelderich, W.F. A Review of Mass Transfer Controlling the Reaction Rate in Heterogeneous Catalytic Systems. In Mass Transfer-Advanced Aspects, 1st ed.; Nakajima, H., Ed.; INTECH: Rijeka, Croatia, 2011; Chapter 29; pp. 667-684. [CrossRef]

37. Levich, V.G. Physicochemical Hydrodynamics; Scripta Technica, Inc., Translator; Prentice-Hall: Englewood Cliffs, NJ, USA, 1962.

38. Newman, J. Schmidt Number Correction for the Rotating Disk. J. Phys. Chem. 1966, 70, 1327-1328. [CrossRef]

39. Yen, S.C.; Wang, J.S.; Chapman, T.W. Experimental Mass Transfer at a Forced-Convective Rotating-Disk Electrode. J. Electrochem. Soc. 1992, 139, 2231-2238. [CrossRef]

40. Ellison, B.T.; Cornet, I. Mass transfer to a Rotating disk. J. Electrochem. Soc. 1970, 118, 68-72. [CrossRef]

41. Lund, K.; Fogler, H.S.; McCune, C.C. Acidization-I. The dissolution of dolomite in hydrochloric acid. Chem. Eng. Sci. 1973, 28, 691-700. [CrossRef]

42. Sayed, M.; Nasr-El-Din, H.A.; Nasrabadi, H. Reaction of emulsified acids with dolomite. J. Can. Pet. Technol. 2013, 52, 164-175. [CrossRef]

43. Taylor, K.C.; Al-Ghamdi, A.H.; Nasr-El-Din, H.A. Effect of Additives on the Acid Dissolution Rates of Calcium and Magnesium Carbonates. SPE Prod. Facil. 2004, 19, 122-127. [CrossRef]

44. Abdelgawad, K.Z.; Mahmoud, M.; Hussein, I. Stimulation of high temperature carbonate gas reservoirs using seawater and chelating agents: Reaction kinetics. J. Nat. Gas Sci. Eng. 2018, 55, 595-605. [CrossRef]

45. Mahmoud, M.A.; Nasr-El-Din, H.A. Modeling flow of chelating agents during stimulation of carbonate reservoirs. Arab. J. Sci. Eng. 2014, 39, 9239-9248. [CrossRef]

(C) 2019 by the authors. Licensee MDPI, Basel, Switzerland. This article is an open access article distributed under the terms and conditions of the Creative Commons Attribution (CC BY) license (http://creativecommons.org/licenses/by/4.0/). 